Determinantes ecológicos do risco de extinção: abundância local, amplitude de nicho, capacidade de dispersão e a resposta das espécies de pequenos mamíferos à fragmentação florestal no
Planalto Atlântico Paulista

Ecological determinants of extinction risk:

local abundance, niche breadth, dispersal ability and response of small mammals to forest fragmentation at the Atlantic Plateau of São Paulo

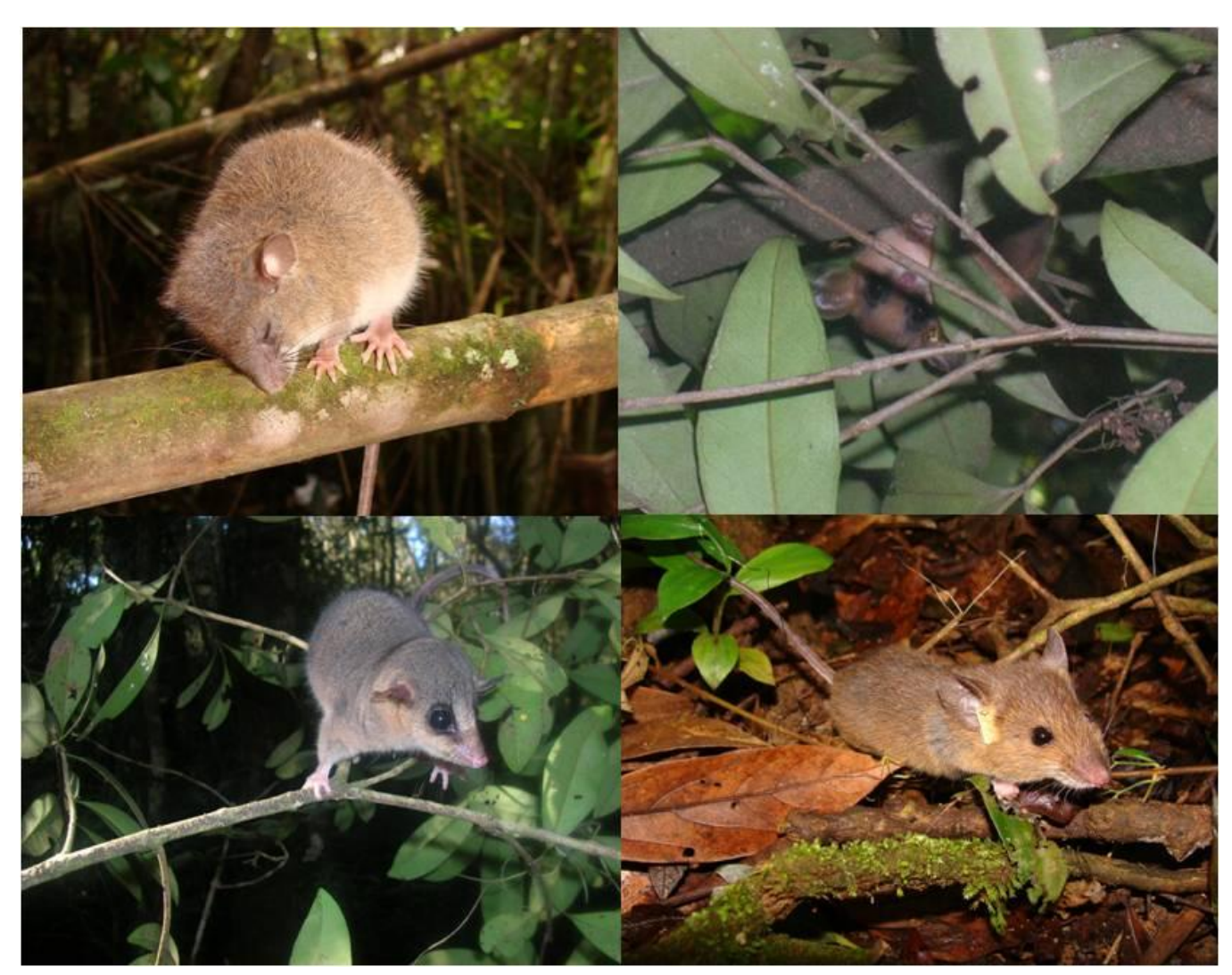

São Paulo 


\title{
Determinantes ecológicos do risco de extinção: abundância local, amplitude de nicho, capacidade de dispersão e a resposta das espécies de pequenos mamíferos à fragmentação florestal no Planalto Atlântico Paulista
}

\author{
Ecological determinants of extinction risk: \\ local abundance, niche breadth, dispersal ability and \\ response of small mammals to forest fragmentation at the \\ Atlantic Plateau of São Paulo
}

Dissertação apresentada ao Instituto de Biociências da Universidade de São Paulo, para a obtenção de Título de Mestre em Ciências, na Área de Zoologia.

Orientadora:Prof ${ }^{\mathrm{a}} \cdot{ }^{\mathrm{D}}{ }^{\mathrm{a}} \cdot$.Renata Pardini

São Paulo 


\section{FICHA CATALOGRÁFICA}

\section{Martins, Thais Kubik}

Determinantes ecológicos do risco de extinção local : abundância local, amplitude de nicho, capacidade de dispersão e a resposta das espécies de pequenos mamíferos à fragmentação florestal no Planalto Atlântico Paulista / Thais Kubik Martins ; orientadora Renata Pardini. São Paulo, 2011.

$70 \mathrm{f}$.

Dissertação (Mestrado) - Instituto de Biociências da Universidade de São Paulo. Departamento de Zoologia

1. Demanda conflitante. 2. Capacidade de deslocamento. 3. Especialização ecológica. 4. Raridade. 5. Fragmentação de habitat. 6. Espécies ameaçadas. 7. Área de vida. 8. Movimento. 9. Perda de habitat. 10. Requerimentos de habitat. I. Universidade de São Paulo. Instituto de Biociências. Departamento de Zoologia. II. Título.

\section{Comissão Julgadora:}

$\operatorname{Prof}(\mathrm{a}) . \operatorname{Dr}(\mathrm{a})$.

$\operatorname{Prof(a).~Dr(a).~}$

Profa. Dr.a.

Orientadora 
Aos meus pais e irmã, por toda dedicação, força e paciência, sempre! 


\title{
Precisamos de você
}

\author{
Aprende - lê nos olhos, \\ lê nos olhos - aprende \\ a ler jornais, aprende: \\ a verdade pensa \\ com tua cabeça.
}

Faça perguntas sem medo não te convenças sozinho mas vejas com teus olhos. Se não descobriu por si na verdade não descobriu.

Confere tudo ponto por ponto - afinal você faz parte de tudo, também vai ao barco, "aí pagar o pato, vai pegar no leme um dia.

Aponte o dedo, pergunta que é isso? Como foi parar aí? Por quê? Você faz parte de tudo.

Aprende, não perde nada das discussões, do silêncio. Esteja sempre aprendendo por nós e por você.

Você não será ouvinte diante da discussão, não será cogumelo de sombras e bastidores, não será cenário para nossa ação.

\section{Eugen Berthold Friedrich Brecht}

(Poemas - 1913-1956. Traduzido por Paulo Cesar Souza) 


\section{AGRADECIMENTOS}

À Renata, pela verdadeira orientação ao longo de tantos anos, pelos inúmeros ensinamentos, sobre ciência e sobre a vida, profissional e pessoal. Obrigada pela oportunidade de trabalhar junto a você!

Ao Thomas, por ter sido tão atencioso e presente durante a co-orientação, sempre me questionando e fazendo pensar a todo instante sobre o mestrado. Você foi fundamental para a conclusão dessa dissertação!

À Camilinha, amiga marsupial, que me deu muito apoio e energia principalmente no final da dissertação, além de me ensinar a gostar de samba!

Àqueles que nos auxiliaram em campo, enfrentando ataques de marimbondo, mordidas de rato, carro esmagado por ônibus, casa pegando fogo, 10 ratos por balde sem lanterna, dias felizes de sol e de chuva torrencial, e com quem pude aprender muito. Em especial ao Mortão, Natali Pineiro, Rafael Conti, Erika Jenifer, Celso Parruco, Rogério, Camila Armstrong e aos mastozoólogos Mônica Coelho, Bamboo, Napister, Aline Quati. Sem vocês não teríamos feito um bom e divertido trabalho de campo!

Ao Saldanha, que com muita calma superou uma estrada caída e uma ratada durante as últimas amostragens no Morro!

Aos nossos ajudantes de campo, moradores das regiões onde coletamos os dados, em especial ao Seu Vanil, que esteve presente durante anos conosco, em diversos trabalhos de nosso laboratório!

Aos funcionários do I.B., que trabalharam muito e contribuíram para que tivéssemos um local íntegro de trabalho, além de torcerem bastante para que nossos trabalhos dessem certo!

Aos professores do departamento de Ecologia, cujas disciplinas foram fundamentais para a elaboração dessa dissertação. Em especial ao professor Paulo Inácio, que sempre esteve muito presente durante todo o mestrado, com excelentes idéias para as análises e para a vida!

Ao Rudolph, Camila Mandai, Renato Lima, que ajudaram bastante na construção e execução dos scripts, no fantástico R. À Cris Caselli, Marcos Grazinolli, Paula Lira e professor Fernando Fernandez, pelas conversas e conselhos sobre área de vida dos pequenos mamíferos.

Aos amigos que durante anos estiveram juntos no laboratório de Diversidade e Conservação de Mamíferos. A velha- guarda (desculpem-me pelo termo "velha") Fabi, Dri, Laura, Bruno, Nati, a jovem- guarda Pagotta, Jú de Luca, Enrico, Cassano, Gustavo, Karina, Flávia, Fabiano, e às filhotes- guarda Patty, Karina, Gabi e Paulinha que, seja no laboratório, no campo, ou no bar, ajudaram-se sem limites, uns aos outros, mostrando que fomos e somos mais que uma equipe, mas companheiros de verdade! 
Aos amigos paulistanos da "ZL", com quem aprendi a "lutar", "resistir" e "vencer". Aos da “ZO” e do I.B., em especial Caramelo, Melina Polaina, Tropesso, Lili, Véio, Rodrigo e Livia, que sempre deram idéias mais que geniais em meio às angústias e alegrias desta dissertação!

A Pagotta (de novo?), que desde a primeira triagem de artrópodes me ensinou muito sobre os pequenos mamalianos, a vida, o universo e tudo mais!

Ao MBS, por ter me ensinado que os opiliões são astutos e perspicazes, além de muitas vezes endêmicos, e por isso não podemos fazer pouco caso deles, nunca! 


\section{ÍNDICE}

$\begin{array}{lll}\text { Resumo } & 1\end{array}$

$\begin{array}{lr}\text { Abstract } & 2\end{array}$

Introdução

Material e Métodos $\quad 8$

Área de estudo $\quad 8$

Coleta de dados $\quad 8$

Risco de extinção local associado à fragmentação do habitat $\quad 8$

Abundância local 11

$\begin{array}{ll}\text { Capacidade de dispersão } & 12\end{array}$

Amplitude de nicho $\quad 15$

Modelos sobre os determinantes ecológicos do risco de extinção local 15

$\begin{array}{ll}\text { Resultados } & 19\end{array}$

$\begin{array}{ll}\text { Espécies de pequenos mamíferos } & 19\end{array}$

Risco de extinção, abundância local, capacidade de dispersão e $\quad 19$ amplitude de nicho

Modelos sobre determinantes ecológicos do risco de extinção local 20

$\begin{array}{ll}\text { Discussão } & 22\end{array}$

Espécies de pequenos mamíferos $\quad 22$

Índice de risco de extinção

Abundância local, capacidade de dispersão e amplitude de nicho 23

$\begin{array}{ll}\text { Determinantes do risco de extinção } & 27\end{array}$

$\begin{array}{ll}\text { Referências } & 30\end{array}$

\section{Tabelas}

$\begin{array}{ll}\text { Tabela } 1 & 37\end{array}$

$\begin{array}{ll}\text { Tabela } 2 & 38\end{array}$

Tabela $3 \quad 39$

$\begin{array}{ll}\text { Tabela } 4 & 40\end{array}$

$\begin{array}{ll}\text { Tabela } 5 & 41\end{array}$

$\begin{array}{ll}\text { Tabela } 6 & 42\end{array}$ 
Tabela 7

Tabela 8

\section{Figuras}

Figura 1

Figura 2

Figura 3

Figura 4

Anexos

Anexo 1

Anexo 2

Anexo 3

Anexo 4 55

Anexo 5 56

Anexo 6 57

Anexo 7 59

Anexo 8

60 


\section{RESUMO}

Alterações antrópicas nos ecossistemas, em especial a perda e a fragmentação de habitat, são consideradas as principais causas do grande aumento nas extinções de espécies nas últimas décadas. Uma vez que o risco de extinção varia grandemente entre as espécies, os determinantes ecológicos associados à chance de extinção têm sido um tema central e muito debatido na literatura ecológica. Atributos ecológicos relacionados à raridade, como amplitude de nicho e abundância local, e a capacidade de dispersão são recorrentemente citados na literatura como determinantes do risco de extinção local. A partir de dados de ocorrência em fragmentos, matas contínuas e áreas de agricultura, e de captura-recaptura em três grades de 2 ha em mata continua, no Planalto Atlântico Paulista, investigamos o efeito desses três atributos ecológicos sobre o risco de extinção local em espécies de pequenos mamíferos. Utilizamos a abordagem de seleções de modelos e o critério de Akaike (AICc) para avaliar qual das hipóteses existentes na literatura sobre a relação destes atributos com o risco de extinção é mais plausível. Foram realizadas duas seleções de modelos: uma considerando os três atributos para sete espécies; e outra considerando apenas a amplitude de nicho e abundância local para 18 espécies. Os resultados de ambas as seleções indicam a amplitude de nicho como determinante principal do risco de extinção local, que aumenta à medida que a amplitude de nicho diminui. Abundância local apresentou uma importância secundária, com um efeito positivo sobre o risco de extinção, mas que é mais forte para espécies com menor amplitude de nicho. Este resultado é consistente com a idéia de que a abundância local é influenciada pelo grau de especialização e pela capacidade competitiva das espécies, a qual está negativamente relacionada à capacidade de colonização através de uma demanda conflitante. Como a capacidade de dispersão variou pouco entre as espécies estudadas e a capacidade de colonização é determinada também pela taxa de crescimento populacional, é possível que o risco de extinção das espécies de pequenos mamíferos especialistas de habitat seja secundariamente definido pela taxa de crescimento populacional.

Palavras-chave: área de vida, capacidade de deslocamento, demanda conflitante, espécies ameaçadas, fragmentação de habitat, movimento, perda de habitat, raridade, requerimentos de habitat, especialização ecológica 


\begin{abstract}
Anthropogenic disturbances, particularly habitat loss and fragmentation, are considered the main causes of the increased extinction rates observed in the last decades. Since the risk of extinction is extremely variable among species, the ecological determinants of the chance of extinction have been in the center of the debates in the ecological literature. Ecological traits associated with rarity, as niche breadth and local abundance, and dispersal ability are recurrently mentioned in the literature as the main determinants of the risk of local extinction. Using data on occurrence in fragments, continuous forest and areas of agriculture, and on capture-recapture in three 2-ha grids in continuous forest, in the Atlantic Plateau of São Paulo, we investigate the effects of these three ecological traits on the risk of local extinction in small mammals. We used a model selection approach and the Akaike criterion (AICc) to evaluate which of the existing hypotheses on the relationship of these traits with the extinction risk is most plausible. Two model selections were run: one considering the three traits and seven species, and another considering only niche breadth and local abundance and 18 species. The results from both selections point to niche breadth as the main determinant of the risk of local extinction. Local abundance was secondarily important, with a positive effect on extinction risk, which is stronger among the species with smaller niche breadth. This result is consistent with the idea that local abundance is influenced by species degree of ecological specialization and competitive ability, which is negatively related to colonization ability through a trade-off. As dispersal ability varied little among studied species, and colonization ability is also determined by population growth rate, it is possible that the risk of extinction among habitat specialist small mammals is secondarily defined by population growth rate.
\end{abstract}

Key-words: home range, trade-off, endangered species, habitat fragmentation, movement, habitat loss, rarity, habitat requirements, ecological specialization 


\section{INTRODUÇÃO}

Alterações antrópicas nos ecossistemas, em especial a perda e a fragmentação de habitat, são consideradas as principais causas de extinções de espécies nas últimas décadas (Henle et al., 2004; Isaac et al., 2009). Essas interferências humanas têm elevado as taxas de extinção atuais, levando ao que pode ser considerada a sexta extinção em massa na Terra (Barnosky et al., 2011). No entanto, dada a variação nos atributos ecológicos e de história de vida, as respostas às alterações antrópicas e consequentemente o risco de extinção variam amplamente entre as espécies (McIntyre, 1992; McKinney, 1997; Henle et al., 2004; Mace et al., 2008; Isaac et al., 2009). Assim, os atributos determinantes do risco de extinção têm sido um tema central e muito debatido na literatura ecológica (McKinney, 1997; Purvis et al., 2000a; Henle et al., 2004; Watling e Donnelly, 2007; Vetter et al., 2011). A definição dos atributos ecológicos que determinam o risco de extinção das espécies é também crucial para o delineamento de estratégias de conservação (McKinney, 1997; Mace et al., 2008; Isaac et al., 2009).

Muitos são os atributos ecológicos propostos na literatura, a partir de modelos teóricos e trabalhos empíricos, como sendo os mais importantes para determinar o risco de extinção das espécies (McKinney, 1997; Davies et al., 2000; Reynolds, 2003; Henle et al., 2004). Muitos destes atributos, no entanto, são altamente correlacionados, o que dificulta a compreensão e definição dos principais determinantes do risco de extinção (Pimm et al., 1988; Gaston, 1994; Purvis et al., 2000a; Ewers e Didham, 2006).

Tamanho do corpo, longevidade e fecundidade (i.e. idade de maturação sexual, tempo de geração, tamanho de prole, intervalo de gestações), por exemplo, são características recorrentemente citadas como determinantes da extinção e são altamente correlacionadas (Pimm et al., 1988; Laurance, 1991; McKinney, 1997; Henle et al., 2004). Espécies com maior tamanho corpóreo geralmente têm maior longevidade e menor fecundidade (Pimm et al., 1988; Gaston e Blackburn, 2000; Purvis et al., 2000a). Essas características estão também associadas a um atributo estreitamente relacionado à chance de extinção (Pimm et al., 1988; McKinney, 1997; Davies et al., 2000; Mace et al., 2008), o menor tamanho populacional (Kunin e Gaston, 1993; Gaston e Blackburn, 2000). Assim, o tamanho populacional ou raridade da espécie (e.g. Brown, 1984; McKinney, 1997; Reynolds, 2003 Ewers e Didham, 2006) tem sido considerado um dos atributos chave associados ao risco de extinção (Gaston 1994), já que a redução do tamanho populacional antecede a extinção (Davies et al., 2000; Reynolds, 2003). Por outro lado, trabalhos empíricos (e.g. Pires et al., 2002; Ims e Andreassen, 2005; Moore et al., 2008) e teóricos (e.g. 
Travis e Dytham, 1999; Hanski e Ovaskainen, 2003) têm apontado a capacidade de dispersão como outro atributo importante associado ao risco de extinção.

A raridade, ou tamanho populacional, no entanto, é um atributo complexo, definido por mais de uma característica (McIntyre, 1992; Kunin e Gaston, 1993). Rabinowitz (1981) propôs que a raridade de uma espécie é dada a partir da combinação de três atributos ecológicos principais: distribuição geográfica, amplitude de nicho e abundância local (McIntyre, 1992). A raridade, portanto, descreve uma ampla gama de padrões espaciais de abundância (Kunin e Gaston, 1993; Gaston, 1994). Por exemplo, espécies endêmicas, que são restritas geograficamente, podem apresentar alta abundância local, e espécies com ampla distribuição geográfica podem apresentar baixa abundância local (Gaston, 1994). Por outro lado, a distribuição geográfica é definida pela maneira como estão distribuídos os recursos bióticos e abióticos que a espécie necessita (Brown, 1984; Gaston e Blackburn, 2000; Devictor et al., 2010). Espécies que utilizam diferentes recursos, ou seja, que possuem maior amplitude de nicho, têm maior distribuição geográfica (Brown, 1984; Gaston e Blackburn, 2000; Brown e Lomolino, 2006; Devictor et al., 2010).

Assim, os atributos que determinam a raridade das espécies estão associados à extinção em escalas espaciais distintas (Gaston, 1994; Purvis et al., 2000b; Hartley e Kunin, 2003). O tamanho da distribuição geográfica, por exemplo, está mais associado ao risco de extinção em escala global, já que distribuições geográficas amplas diminuem a chance de extinção global devido alterações locais no ambiente (McIntyre, 1992; Purvis et al., 2000b). Por outro lado, a abundância local e a amplitude de nicho, além da capacidade de dispersão, estão mais associados ao risco de extinção em uma escala local (Purvis et al., 2000b).

Espécies com baixa abundância local apresentam maior risco de extinção por estocasticidade demográfica, ambiental ou genética (Pimm et al., 1988; Lande, 1998; Reynolds, 2003; Mace et al., 2008). Trabalhos empíricos demonstraram que espécies com maior abundância antes de distúrbios, como a fragmentação de habitats, têm menor risco de extinção local (Bolger et al., 1991; Bolger et al., 1997; Davies et al., 2000). Por outro lado, uma espécie com maior amplitude de nicho, ou generalista (Devictor et al., 2010), por ter a capacidade de explorar diferentes recursos, além de uma maior tolerância às alterações em seu ambiente (Gaston et al., 1997; Pulliam, 2000; Clavel et al., 2010; Devictor et al., 2010), terá maiores chances de se adaptar a mudanças naturais ou antrópicas ocorridas no ambiente (Laurance 1991; Manor e Saltz, 2008; Isaac et al., 2009), sofrendo menor risco de extinção local.

Há poucos estudos que quantificaram empiricamente a capacidade de dispersão das espécies (e.g. Cadotte et al., 2006, para protozoários; Diffendorfer et al., 1995 e Ims e 
Andreassen, 2005, para pequenos mamíferos; Moore et al., 2008, para aves; Thomas et al., 2000 e Öckinger et al., 2010, para borboletas), atributo ecológico difícil de ser quantificado (Ims e Andreassen, 2005). Assim, a importância da capacidade de dispersão para a chance de extinção local das espécies foi abordada principalmente através de modelos teóricos e simulações (e.g. Travis e Dytham, 1999; With e King, 1999; Amarasekare e Nisbet, 2001; Hanski e Ovaskainen, 2003), e existem hipóteses concorrentes e contraditórias sobre o efeito deste atributo.

Por um lado, quando há alterações no ambiente, espécies com elevada capacidade de dispersão podem alcançar outras manchas de habitat, tendo, assim, menor risco de extinção (Andrén, 1994; Pires et al., 2002; Hanski e Ovaskainen, 2003). Além disso, uma elevada capacidade de dispersão aumenta as chances de re-colonização de manchas de habitat onde a espécie se extinguiu localmente (Haila, 2002; Fahrig, 2003; Tilman, 2004; Ewers e Didham, 2006) e diminui as chances de extinção local pelo efeito resgate (sensu Brown e Kodric-Brown, 1977). O efeito resgate pode aumentar o tamanho das populações nas manchas de habitat remanescentes (Moilanen e Hanski, 1998; Gaston e Blackburn, 2000; Reynolds, 2003), diminuindo-se as chances de extinção por efeitos estocásticos, mais prováveis de ocorrer em menores populações (Pimm et al., 1988; Moilanen e Hanski, 1998).

Por outro lado, pode haver um aumento no risco de mortalidade durante a dispersão em ambientes alterados (Lande, 1998; Travis e Dytham, 1999; Thomas, 2000; Fahrig, 2002). Além disso, espécies com elevada capacidade de dispersão geralmente têm maior requerimento de área (Thomas, 2000; Bowman et al., 2002), sendo mais sensíveis a alterações que causem redução do habitat remanescente. Assim, por se deslocarem com maior frequiência entre as manchas de habitat, espécies com maior capacidade de dispersão sofreriam maior mortalidade, apresentando maior risco de extinção. Ao contrário, espécies com baixa capacidade de dispersão têm menor requerimento de área (Thomas, 2000) e por isso podem persistir nas manchas de habitat remanescentes (Thomas, 2000; Rodríguez et al., 2007), tendo menor risco de extinção associado ao deslocamento em um ambiente alterado (Travis e Dytham, 1999; Pires et al., 2002).

Outra hipótese concorrente quanto à capacidade de dispersão e o risco de extinção foi apresentada por Thomas (2000). Em um trabalho empírico com borboletas, o autor encontrou que as espécies que se deslocavam por distâncias intermediárias foram as espécies com maior risco de extinção local associado à fragmentação de habitat. A hipótese levantada pelo autor sugere que os indivíduos de espécies com capacidade de dispersão intermediária emigram, mas falham em alcançar um novo habitat. Assim, não só a mortalidade associada a dispersão é alta, mas também o efeito resgate é baixo, já que os indivíduos emigrantes não são substituídos por indivíduos imigrantes. 
Por fim, teorias em ecologia de comunidades sugerem que haja interações importantes entre os três atributos ecológicos - abundância local, amplitude de nicho e capacidade de dispersão - que definem o risco de extinção local. Estas interações estão relacionadas à capacidade competitiva das espécies e à demanda conflitante entre capacidade competitiva e capacidade de colonização (Rabinowitz et al., 1984; Nee e May, 1992; Tilman, 1994; Cadotte et al., 2006).

A amplitude de nicho, ou grau de especialização ecológica, está relacionada à capacidade competitiva (Tilman, 1994; Pulliam, 2000; Clavel et al., 2010; Devictor et al., 2010) e também à abundância local das espécies (Rabinowitz et al., 1984; Gaston e Blackburn, 2000; Manor e Saltz, 2008; Isaac et al., 2009; Williams et al., 2009). Quanto maior o grau de especialização, maior a capacidade competitiva das espécies nos ambientes em que os recursos em que são especializadas são comuns, consequentemente resultando em uma maior abundância local (Gaston et al., 1997; Pulliam, 2000; Glazier e Eckert, 2002; Clavel et al., 2010; Devictor et al., 2010). Porém, quanto maior o grau de especialização, menor a capacidade de suportar alterações ou perturbações no ambiente, já que espécies especialistas têm menor plasticidade fenotípica e fisiológica (Manor e Saltz, 2008).

Além disso, uma série de trabalhos sugere que haja uma demanda conflitante entre capacidade competitiva e capacidade de colonização, que seria responsável por permitir a coexistência de espécies competidoras superiores e inferiores. Espécies com alta capacidade competitiva (e alta abundância local) apresentariam necessariamente baixa capacidade de colonização, por apresentar baixa capacidade de dispersão (Tilman, 1994; Tilman, 2004; Rodríguez et al., 2007; Burton et al., 2010), ou baixa capacidade de crescimento populacional (Tilman, 1994; Cadotte et al., 2006; Burton et al., 2010). Segundo esta hipótese de demanda conflitante, as espécies competidoras inferiores serão abundantes somente em manchas de habitat onde a espécie melhor competidora não estiver presente, ou em manchas não alcançadas por esta espécie, que possui baixa capacidade de colonização (Amarasekare e Nisbet, 2001).

Embora a existência destas interações e demandas conflitantes não altere as relações esperadas e descritas anteriormente entre risco de extinção e tanto a amplitude de nicho quanto a capacidade de dispersão (relação negativa), este não é o caso para a abundância local. Sob a perspectiva de que a abundância local seja um reflexo do grau de especialização ecológica e capacidade competitiva das espécies, espera-se que a maior abundância local leve não a menor (Pimm et al., 1988) mas a um maior risco de extinção (Nee e May, 1992; Tilman, 1994; Manor e Saltz, 2008; Isaac et al., 2009; Williams et al., 2009). Assim, embora os três atributos ecológicos - abundância local, amplitude de nicho e capacidade de dispersão - sejam considerados 
determinantes do risco de extinção local, o sentido e o mecanismo através do qual influenciariam a extinção são pouco conhecidos, e hipóteses diferentes já foram levantadas na literatura (Tabela 1). Além disso, poucos estudos abordaram simultaneamente o efeito destes três atributos (Ewers e Didham, 2006; Thornton et al., 2011; Vetter et al., 2011).

Este trabalho tem por objetivo contribuir com o entendimento de como a abundância local, amplitude de nicho e capacidade de dispersão interagem para determinar o risco de extinção das espécies. Para tanto, escolhemos como sistema de estudo o risco de extinção de espécies de pequenos mamíferos frente o desmatamento e fragmentação da Mata Atlântica do Planalto de São Paulo. A perda e a fragmentação de habitat são os principais processos responsáveis pela atual perda da diversidade de espécies (Fahrig, 2003). O bioma Mata Atlântica, considerado um hotspot de biodiversidade (Myers et al., 2000), atualmente está reduzido a menos de $16 \%$ de sua área original (Ribeiro et al., 2009), e apenas 1,73\% do total de sua área está em unidades de conservação de proteção integral (Silva et al., 2011). Os pequenos mamíferos são um grupo diverso (Fonseca et al., 1996), que responde a perda e a fragmentação do habitat da Mata Atlântica (Pardini, 2004; Viveiros de Castro e Fernandez, 2004; Pardini et al. 2005; Pardini et al., 2010).

O risco de extinção local e a amplitude de nicho das espécies de pequenos mamíferos foram estimados a partir de um banco de dados sobre a ocorrência das espécies em múltiplos sítios em seis paisagens de 10.000 ha no Planalto Atlântico Paulista, que variam quanto à porcentagem de mata remanescente. A abundância local e a capacidade de dispersão, por outro lado, foram estimadas a partir de dados de dois anos de captura-recaptura em três grades de armadilhas em áreas contínuas. A partir destes dados, usando a abordagem de seleção de modelos verificamos qual das hipóteses disponíveis na literatura a respeito dos efeitos da abundância local, amplitude de nicho e capacidade de dispersão das espécies sobre o risco de extinção local (Tabela 1) são mais plausíveis. 


\section{MATERIAIS E MÉTODOS}

\section{Área de estudo}

O estudo foi realizado na região do Planalto Atlântico Paulista. Toda a região era originalmente coberta por floresta Atlântica, classificada como Floresta Atlântica baixo montana (Oliveira-Filho e Fontes, 2000). A altitude da região varia de 800 a 1000 metros, com pluviosidade anual entre 1220 a 1810 mm (Ross e Moroz, 1997), temperaturas mínima e máxima de $17,3^{\circ} \mathrm{C}$ e $28,4^{\circ} \mathrm{C}$ nos meses mais quentes e chuvosos (outubro a março), e de $12,1^{\circ} \mathrm{C}$ e $24,9^{\circ} \mathrm{C}$ nos meses mais frios e secos (abril a setembro).

Foram estudadas três regiões do Planalto Atlântico Paulista, compreendendo os municípios de Tapiraí e Piedade, Cotia e Ibiúna, e Ribeirão Grande e Capão Bonito. Em cada uma das regiões foram amostradas uma paisagem de mata contínua e outra de mata fragmentada, perfazendo ao todo seis paisagens de 10.000 ha (Figura 1). As três paisagens de mata contínua fazem parte do maior contínuo de Mata Atlântica do Brasil, a Serra do Mar (Ribeiro et al., 2009) e as três paisagens de mata fragmentada apresentavam diferentes porcentagens de mata remanescente, com 49\% de mata remanescente em Tapiraí e Piedade, 31\% em Cotia e Ibiúna e $11 \%$ em Ribeirão Grande e Capão Bonito. Maiores detalhes sobre as paisagens de estudo podem ser encontrados em Pardini et al. (2010).

\section{Coleta de dados em campo}

\section{Risco de extinção e amplitude de nicho}

Dados sobre a ocorrência e número de indivíduos das espécies de pequenos mamíferos nas três regiões do Planalto Atlântico Paulista foram obtidos a partir de estudos anteriores (Bueno, 2008; Pardini et al., 2010; Umetsu et al. 2010). Nestes estudos, foram amostrados de maneira padronizada um total de 104 sítios, sendo 68 em matas (Bueno, 2008; Pardini et al., 2010) e 36 em áreas de agricultura de cultivos anuais (Umetsu et al., 2010).

Entre os 68 sítios em matas, 50 estavam localizados em fragmentos (15 na paisagem fragmentada de Tapiraí e Piedade, 20 na paisagem fragmentada Cotia e Ibiúna e 15 na paisagem fragmentada de Ribeirão Grande e Capão Bonito) e 18 em matas contínuas (seis em cada uma das três regiões) (Figura 1). Entre os 36 sítios em áreas de agricultura, 18 estavam localizados na paisagem fragmentada mais florestada (Tapiraí e Piedade) e 18 na paisagem fragmentada menos florestada (Ribeirão Grande e Capão Bonito). 


\section{Abundância local e capacidade de dispersão}

Em uma das três paisagens contínuas estudadas no Planalto Atlântico Paulista, a Reserva Florestal do Morro Grande, foram obtidos dados de captura-recaptura das espécies de pequenos mamíferos em três sítios em estádio médio de regeneração, distando ao menos um quilômetro entre si (Figura 1). Cada sítio continha uma grade com dois tipos de armadilhas de contenção viva (shermans e armadilhas de interceptação e queda). Cada grade foi composta por 11 linhas paralelas de armadilhas, cada uma com $100 \mathrm{~m}$ de comprimento e distando $20 \mathrm{~m}$ entre si, abrangendo uma área total de 2 ha $(100 \mathrm{~m}$ x $200 \mathrm{~m})$. Seis das 11 linhas continham apenas armadilhas do tipo sherman e, intercalando-se a elas, cinco linhas continham armadilhas de interceptação e queda e shermans (Figura 2).

As linhas de interceptação e queda continham 11 baldes de 60 litros a cada $10 \mathrm{~m}$. Os baldes foram conectados por cercas-guia de lona plástica, com altura de $50 \mathrm{~cm}$. Para evitar o acúmulo de água durante o período de chuvas, o fundo dos baldes foi furado e sobre os baldes foram colocadas tampas apoiadas em estacas. Além disso, placas de isopor foram colocadas dentro dos baldes, para aumentar as chances de sobrevivência do animal, caso enchessem de água. Ao lado dos baldes foram colocadas armadilhas sherman, totalizando 11 shermans por linha. As linhas de sherman continham apenas 11 armadilhas sherman a cada $10 \mathrm{~m}$. Cada grade de armadilhas continha, portanto, 121 shermans e 55 baldes.

A amostragem das populações de pequenos mamíferos, por meio da captura, marcação e recaptura nas grades de armadilhas, teve início em março de 2008 e término em outubro de 2009. As sessões de amostragem tiveram um intervalo de no máximo 30 dias e no mínimo 16 (média de 23,4 dias) totalizando 21 sessões, cada uma com cinco dias consecutivos, resultando em um esforço total de 55.440 armadilhas-noite. Todas as armadilhas foram checadas e iscadas diariamente. A isca foi composta por pasta de amendoim, sardinha, banana e fubá ou aveia, componentes que são efetivos na atração de pequenos mamíferos (Voss et al. 2001).

A identificação das espécies capturadas foi realizada a partir do conhecimento prévio sobre as características morfológicas externas compiladas em Rossi (2011). Três pares de espécies do mesmo gênero são de difícil identificação a partir da morfologia externa (Rossi, 2011) e foram consideradas conjuntamente nas análises de dados: Juliomys pictipes e J. ossitenuis, Monodelphis scalops e M. americana, e Phyllomys nigrispinus e P. sulinus.

Os indivíduos capturados foram anestesiados e tiveram uma orelha marcada com brinco metálico numerado para a identificação individual. Na primeira captura de um indivíduo e também na primeira recaptura em todas as sessões posteriores, foram anotados tamanho corpóreo, peso, sexo, classe etária e condição reprodutiva. Posteriormente, os indivíduos foram 
soltos próximos às armadilhas em que foram capturados. Para os indivíduos capturados mais de uma vez em uma mesma sessão de amostragem, apenas o ponto de captura e o tipo de armadilha foram registrados. Em poucas ocasiões, os animais foram encontrados mortos na armadilha ou morreram durante o manuseio. Os animais mortos foram taxidermizados e o esqueleto, estômago, fígado e fezes desses animais foram coletados.

A classe etária dos roedores foi determinada pela coloração de sua pelagem e pelas proporções do corpo, separando-os em jovens, subadultos e adultos. Para os marsupiais, a classe etária foi inferida a partir da fórmula dentária dos indivíduos (Macedo et al., 2006). Para determinar a condição reprodutiva das fêmeas de marsupiais e roedores, foram registradas a ocorrência de gravidez e a condição das mamas (inchadas ou não). Já para os machos, a determinação por caracteres externos é confiável apenas para roedores, dos quais foi registrada a posição do testículo (abdominal ou escrotal) (Bergallo e Magnusson, 2004).

\section{Risco de extinção local associado à fragmentação de habitat}

Para caracterizar o risco de extinção local das espécies de pequenos mamíferos associado à fragmentação de habitat, foi criado um índice que leva em consideração a ocorrência dessas espécies em 18 sítios de mata contínua (três paisagens, seis sítios por paisagem) e em 50 fragmentos florestais (três paisagens, 15 a 20 fragmentos por paisagem) (Bueno, 2008; Pardini et al., 2010). O índice foi obtido pela diferença entre a porcentagem de sítios com registros da espécie na mata contínua (ambiente original) e a porcentagem de fragmentos florestais com registro das espécies (ambiente alterado pela fragmentação).

Um índice semelhante foi utilizado também por Thornton e colaboradores (2011) em um estudo que mediu o risco de extinção associado à fragmentação de espécies de mamíferos de médio e grande porte. $\mathrm{O}$ índice considera que quanto menor a porcentagem de fragmentos florestais em que a espécie ocorre em relação à porcentagem de sítios ocupados em mata contínua, maior o risco de extinção associado à fragmentação de habitats. Esse índice resulta em um intervalo de valores de $-1 \mathrm{a}+1$, em que as espécies com maior risco de extinção apresentam maiores valores do índice, e é calculado pela fórmula:

$\begin{gathered}\begin{array}{c}\text { Índice do } \\ \text { risco de } \\ \text { extinção local }\end{array} \\ \text { com ocorrência da espécie }\end{gathered}-\begin{gathered}\mathrm{n}^{\circ} \text { sítios mata contínua } \\ 18\end{gathered}-\begin{gathered}\mathrm{n}^{\circ} \text { fragmentos com } \\ \text { ocorrência da espécie }\end{gathered}$




\section{Abundância local}

A abundância pode ser obtida a partir de métodos de enumeração ou de estimação. Métodos de enumeração, que não consideram a probabilidade de captura, subestimam a abundância, principalmente quando a probabilidade de captura é baixa (Krebs, 1999). Já os métodos de estimação consideram a possibilidade de haver diferentes probabilidades de captura, seja entre os indivíduos da população, entre diferentes amostragens, ou entre diferentes capturas do mesmo individuo, e utilizam essas probabilidades de captura para estimar a abundância (White et al., 1982).

Para obter a abundância local das espécies de pequenos mamíferos capturadas na Reserva Florestal do Morro Grande, foram consideradas as três grades de amostragem em conjunto, isto é, as estimativas se referem ao tamanho populacional em uma área de 6 ha. Inicialmente optou-se por um método de estimação, utilizando-se o programa CAPTURE. O programa CAPTURE fornece estimativas de probabilidade de captura e de abundância populacional a partir de dados de captura e recaptura dos indivíduos, em populações fechadas. Cada sessão de amostragem teve duração de cinco dias, período em que uma população de pequenos mamíferos pode ser considerada fechada (i.e. sem mortes, nascimentos, emigração ou migração) (Pollock et al., 1990; Parmenter et al., 2003). A estimativa de abundância realizada no programa é enviesada e pouco precisa quando a probabilidade de captura é menor que 0,1 (White et al., 1982). Assim, foram consideradas apenas as estimativas de abundância das sessões em que a estimativa da probabilidade de captura foi maior que 0,2. No total, foi possível obter 87 estimativas de abundância no CAPTURE para nove espécies de pequenos mamíferos (Anexo 1).

Para a maioria das espécies, no entanto, não foi possível realizar a estimativa de abundância através do CAPTURE, ou porque mesmo com um grande número de indivíduos capturados houve baixa taxa de recaptura, ou porque houve baixo número de indivíduos capturados por sessão de amostragem. Por esse motivo, decidiu-se calcular a abundância populacional também através do MNKA ("minimum number known alive": número mínimo de indivíduos vivos conhecidos) (Krebs, 1999). MNKA é um método de enumeração em que a abundância é calculada em cada sessão de amostragem considerando-se o número de indivíduos capturados naquela determinada sessão e o número de indivíduos que foram capturados tanto na sessão anterior quanto na sessão posterior, mas não na sessão considerada. Assim foi possível obter um valor de abundância para todas as espécies em todas as sessões de amostragem.

O MNKA, apesar de subestimar a abundância local por desconsiderar a probabilidade de captura, pode ser um bom índice da abundância se mantiver as diferenças relativas na abundância entre as espécies. Assumindo que as estimativas do CAPTURE representam uma boa 
estimativa da abundância, foi realizada uma correlação de Pearson entre os valores de MNKA e as estimativas de abundância do CAPTURE para testar se os valores de MNKA podem ser considerados um bom índice de abundância. A correlação foi realizada considerando as 87 estimativas do CAPTURE com probabilidade de captura maior que 0,2 (Anexo 2).

Para obter um único valor que representasse a abundância populacional de cada espécie, foi utilizada a mediana dos valores de MNKA das 21 sessões de amostragem. A decisão de utilizar a mediana foi baseada nas seguintes observações: 1) a distribuição de frequiências dos valores de MNKA das espécies que foram capturadas em pelo menos 15 sessões de amostragem foi semelhante à distribuição normal; e 2) a mediana é uma medida representativa de tendência central para distribuições que se aproximam de uma distribuição normal, mas é mais robusta que a média a valores extremos da amostra quando o tamanho da amostra é pequeno.

\section{Capacidade de dispersão}

A área de vida é uma medida útil para acessar a capacidade de dispersão em mamíferos (Bowman et al., 2002), já que ambas as medidas de uso do espaço são altamente correlacionadas. Dessa maneira, para caracterizar a capacidade de dispersão das espécies de pequenos mamíferos da Reserva Florestal do Morro Grande, optou-se inicialmente por utilizar estimativas da área de vida.

A área de vida foi estimada através do método do Mínimo Polígono Convexo (MPC), obtido a partir do mapeamento dos pontos de captura de cada indivíduo através do programa ArcMap 9.2 (ESRI, 1999-2006) e do pacote Hawth's Analysis (Beyer, 2004). O MPC é construído conectando-se os pontos de capturas mais externos de um indivíduo, sem que o ângulo entre esses pontos exceda $180^{\circ}$, gerando assim um polígono que representa os limites externos da área de vida (Mohr, 1947).

Uma premissa para a utilização do MPC é que os pontos de captura sejam estatisticamente independentes (Swihart e Slade, 1985; Laver e Kelly, 2008). Portanto apenas os primeiros pontos de captura dos indivíduos em cada sessão de amostragem foram considerados. Neste estudo, em particular, há mais uma razão para não utilizar os pontos de captura de uma mesma sessão de amostragem para estimar a área de vida: o uso de cercas-guia nas armadilhas de interceptação e queda, erguidas durante os cinco dias das sessões de amostragem, impedem e/ou dificultam o deslocamento dos indivíduos.

Além disso, a estimativa de área de vida é influenciada pelo número de pontos de captura (Stickel, 1954; Schoener, 1981; Börger et al., 2006; Laver e Kelly, 2008), e estimativas de área de vida baseadas em poucos pontos de captura são subestimadas (Schoener, 1981). Diferentes 
trabalhos realizaram estimativas de área de vida de pequenos mamíferos com pelo menos cinco pontos de captura (e.g. Fernandez, 1989; Lira, 2005; Püttker et al., no prelo), um número suficiente para alcançar uma assíntota da estimativa (Stickel, 1954). Neste trabalho calculamos o MPC para os indivíduos com pelos menos três, quatro e cinco pontos de captura (Anexo 3). Dado que as estimativas com pelo menos quatro pontos de captura foram semelhantes às estimativas com pelo menos cinco pontos de captura (Anexo 3), optou-se por considerar as estimativas com pelo menos quatro pontos de captura para representar a capacidade de dispersão das espécies, já que estas permitem calcular a área de vida para um número maior de indivíduos. No total, a estimativa de área de vida com pelo menos quatro pontos de captura foi possível para indivíduos de sete espécies de pequenos mamíferos, mas para três dessas espécies foi possível obter a estimativa para apenas 1 e 3 indivíduos (Anexo 3).

Como para maioria das espécies de pequenos mamíferos o número de indivíduos com pelo menos quatro capturas foi muito baixo ou inexistente, optou-se por utilizar outra métrica - a distância máxima percorrida entre sessões de amostragem - para caracterizar a capacidade de dispersão. Vários trabalhos verificaram a correlação entre estimativas de área de vida e distâncias percorridas para dados de captura e recaptura (Slade e Swihart, 1983; Slade e Russell, 1998; Mendel e Vieira, 2003; Püttker et al., no prelo).

Para calcular a distância máxima percorrida, foram consideradas apenas as distâncias percorridas entre sessões de amostragem sucessivas, e incluídas apenas a primeira captura por sessão pelos mesmos motivos mencionados anteriormente. A distância percorrida entre sessões foi representada pela distância euclidiana entre as armadilhas em que o indivíduo foi capturado em duas sessões de amostragem sucessivas (considerando a primeira captura por sessão). As distâncias foram calculadas através do programa ArcMap 9.2 (ESRI, 1999-2006), com o uso do pacote Hawth's Analysis (Beyer, 2004).

Para vários indivíduos obteve-se mais de um valor de distância percorrida entre sessões sucessivas e a distância máxima percorrida por cada um deles foi selecionada. Para os indivíduos que apresentaram apenas uma distância percorrida, esse único valor foi utilizado. Assim, poderia haver uma maior probabilidade de obter valores de máxima distância percorrida maiores para indivíduos com um maior número de distâncias percorridas. No entanto, para a espécie com maior número de indivíduos com pelo menos um valor de distância percorrida entre sessões sucessivas (Akodon montensis) houve uma fraca correlação positiva entre o número de valores de distância percorrida e os valores de distância máxima percorrida $(r=0,2243, p=0,0190$; Anexo $4)$. 
Foi possível obter dados de distância máxima percorrida entre sessões de amostragem sucessivas para pelo menos 10 indivíduos de sete espécies de pequenos mamíferos. Para verificar se a distância máxima percorrida é um bom índice da estimativa do tamanho da área de vida, foi realizada uma correlação de Pearson entre os valores de distância máxima percorrida e as estimativas de MPC com pelo menos quatro pontos de captura para os indivíduos das sete espécies de pequenos mamíferos em que estes dados puderam ser calculados (Anexo 5).

Com a finalidade de obter um único valor de distância máxima percorrida para cada espécie, foi investigada qual distribuição de probabilidades teórica melhor se ajusta aos valores de distância máxima percorrida para cada espécie. Para a maioria das espécies, os dados de distância máxima percorrida não se aproximaram de uma distribuição normal, de modo que o uso de uma medida de tendência central como a média ou mediana não seria adequado (Gotelli e Ellison, 2004). Desta forma, foram ajustadas as distribuições teóricas para variáveis contínuas exponencial, weibull, gamma, lognormal e normal, truncadas no valor de maior distância euclidiana possível entre armadilhas nas grades de estudo (223,60 metros). Para cada espécie, foi selecionada a distribuição que obteve o melhor ajuste por máxima verossimilhança (Anexo 6). A análise foi realizada apenas para as sete espécies em que houve 10 ou mais valores de distâncias máximas percorridas (10 ou mais indivíduos capturados em pelo menos duas sessões sucessivas).

Como houve diferentes distribuições teóricas selecionadas entre as espécies, não foi possível utilizar os parâmetros das distribuições para representar a capacidade de dispersão de cada espécie, já que cada distribuição teórica tem parâmetros distintos. Além disso, a interpretação biológica dos parâmetros das distribuições nem sempre é intuitivo (Mandai, 2010). Optou-se, portanto, por selecionar um quantil que englobasse a cauda das distribuições teóricas para representar a capacidade de dispersão de cada espécie. Em todos os casos, apenas os quantis 0,85 em diante englobaram a cauda das distribuições (Anexo 7). Para selecionar um destes quantis, foi realizada uma correlação de Pearson entre eles. A correlação entre os três quantis $(0,85,0,90$ e 0,95$)$ foi maior entre o quantil 0,90 e os quantis 0,85 e 0,95 , sendo estes últimos menos correlacionados entre si (quantil 0,85 e 0,90: $\mathrm{r}=0,8571, \mathrm{p}=0,014$, quantil 0,90 e 0,95: $\mathrm{r}=0,9515, \mathrm{p}<0,001$, quantil 0,85 e 0,95: r=0,7107, p=0,073). Optou-se, portanto, por utilizar o quantil 0,90 da distribuição teórica melhor ajustada aos dados para representar a máxima distância percorrida de cada espécie.

Os procedimentos de ajuste, truncamento de distribuições de probabilidades teóricas e seleção da distribuição por meio de máxima verossimilhança foram realizados no ambiente computacional R (R, 2010). 


\section{Amplitude de nicho}

A amplitude de nicho de uma espécie pode ser acessada através de diferentes informações sobre sua história natural (Gaston e Blackburn, 2000; Brown e Lomolino, 2006). A informação disponível mais refinada que se tem atualmente sobre a amplitude de nicho das espécies de pequenos mamíferos do Planalto Atlântico Paulista diz respeito a apenas um aspecto do nicho, o requerimento de habitat (Rossi, 2011).

Rossi (2011) compilou informações sobre a ocorrência das espécies de pequenos mamíferos em 18 sítios de mata contínua (três paisagens, seis sítios por paisagem) (Bueno, 2008; Pardini et al., 2010) e em 36 sítios em áreas abertas de agricultura (duas paisagens fragmentadas, 18 sítios por paisagem) (Umetsu, 2010). A partir da comparação dessas informações advindas de dois ambientes muito distintos entre si, Rossi (2011) definiu quatro categorias de requerimento de habitat, que foram usadas nesse trabalho para definir a amplitude de nicho (i.e. o grau de especialização em florestas nativas):

a) alta especialização no habitat florestas nativas - espécie que ocupa uma proporção maior de sítios em áreas de mata contínua em relação às áreas de agricultura, e não ocorre nas áreas de agricultura da paisagem muito desmatada;

b) média especialização no habitat florestas nativas - espécie que ocupa uma proporção maior de sítios em áreas de mata contínua em relação às áreas de agricultura, mas ocorre também nas áreas de agricultura da paisagem muito desmatada;

c) baixa especialização no habitat florestas nativas - espécie que ocupa proporções semelhantes de sítios nas áreas de mata contínua e nas áreas de agricultura;

d) não especializada no habitat florestas nativas - espécie que ocupa uma proporção de sítios maior nas áreas de agricultura em relação às áreas de mata contínua.

\section{Modelos sobre os determinantes ecológicos do risco de extinção local}

Foram realizadas correlações de Pearson entre as variáveis independentes abundância local, capacidade de dispersão e amplitude de nicho, para verificar se havia multicolinearidade entre elas. Todas as correlações foram não significativas, indicando que as variáveis independentes apresentam significado biológico distinto (Gotelli e Ellison, 2004). Os modelos candidatos representam hipóteses ecológicas concorrentes, disponíveis na literatura, sobre a influência da abundância local, capacidade de dispersão e amplitude de nicho sobre o risco de extinção das espécies, tendo sido construídos a partir do conhecimento prévio sobre o sistema ecológico em estudo (Burnham e Anderson, 2002; Hobbs e Hilborn, 2006). 
Já que para muitas espécies não foi possível obter a variável independente distância máxima percorrida, foram realizadas duas seleções de modelos, que diferiram quanto ao número de espécies e número de variáveis independentes incorporadas aos modelos. Houve, assim, um maior número de variáveis independentes consideradas nos modelos, mas para um menor número de espécies na primeira seleção de modelos, e um menor número de variáveis independentes, mas para um maior número de espécies na segunda seleção de modelos. Em todos os casos, a variável dependente "risco de extinção local” foi modelada como uma variável normal.

Na primeira seleção, o conjunto de modelos candidatos foi construído considerando-se as três variáveis independentes (amplitude de nicho, capacidade de dispersão e abundância local). As espécies incluídas nesse primeiro conjunto de modelos foram aquelas em que foi possível obter a variável dependente distância máxima percorrida (perfazendo um total de sete espécies), a variável operacional da capacidade de dispersão. O pequeno número de espécies que puderam ser incluídas nesse primeiro conjunto de modelos não permite a construção de modelos com mais de uma variável independente, e, portanto, não permite a consideração dos efeitos aditivos ou das interações entre as variáveis independentes (Burnham e Anderson, 2002). Assim, todos os quatro modelos matemáticos construídos nessa primeira seleção foram simples, contendo apenas uma variável independente, além de um modelo nulo (sem variável independente) (Modelos A a E abaixo, Tabela 1). Dado o pequeno número de espécies, que abarcavam apenas parte da variação na amplitude de nicho, essa variável foi tratada como uma variável categórica, contendo dois níveis (menor e maior amplitude de nicho).

Na segunda análise, o conjunto de modelos candidatos foi construído considerando-se apenas as variáveis independentes amplitude de nicho e abundância local, as quais foram calculadas para um número maior de espécies (18 espécies). Com a inclusão de 18 espécies, foi possível construir não apenas os modelos simples contendo cada uma das duas variáveis e o modelo nulo, mas também modelos múltiplos que consideram ou apenas o efeito aditivo ou o efeito aditivo e a interação entre elas, totalizando cinco modelos concorrentes (Modelos A e D a G abaixo, Tabela 1). Nesta seleção, devido ao maior número de espécies, a variável amplitude de nicho foi tratada como uma variável ordinal, com valores de 1 a 4 (de alta especialização a não especializado no habitat florestas nativas).

A avaliação dos modelos mais plausíveis foi feita a partir dos valores de AICc (critério de informação de Akaike, para amostras pequenas). O AICc possui um fator de correção que leva em consideração o tamanho da amostra, em relação ao número de parâmetros do modelo. Burnham e Anderson (2002) indicam a utilização de AICc quando a razão entre tamanho 
amostral e número de parâmetros do modelo é menor que 40, como é aqui o caso. Modelos que possuíram diferenças no valor de AICc pouco maiores que 2 em relação ao modelo mais plausível, foram incluídos na discussão dos resultados por ainda terem uma capacidade explanatória substancial (Burnham e Anderson, 2002). Os modelos candidatos foram:

A) Modelo nulo, que considera que o valor esperado da variável dependente risco de extinção local é uma constante, não havendo efeito da capacidade de dispersão, da amplitude de nicho, ou da abundância das espécies (hipótese 1- Tabela 1).

B) Os valores esperados da variável dependente risco de extinção local são uma função linear da variável independente capacidade de dispersão. A este modelo matemático estão associadas duas hipóteses propostas na literatura. Uma delas propõe que quanto maior a capacidade de dispersão maior o risco de extinção local, resultando em uma inclinação positiva da reta da regressão (hipótese 2- Tabela 1). A segunda hipótese propõe que quanto maior a capacidade de dispersão menor o risco de extinção local, resultando em uma inclinação negativa da reta da regressão (hipótese 3- Tabela 1).

C) Os valores esperados da variável dependente risco de extinção são uma função de segunda ordem (parábola) da variável independente capacidade de dispersão. A hipótese associada a este modelo propõe que capacidades de dispersão intermediárias estão associadas ao maior risco de extinção da espécie, resultando na concavidade da parábola voltada para cima (hipótese 4Tabela 1).

D) Os valores esperados da variável dependente risco de extinção são uma função linear da variável independente abundância local. A este modelo matemático estão associadas duas hipóteses propostas na literatura. Uma delas propõe que quanto maior a abundância local menor o risco de extinção, resultando em uma inclinação negativa da reta da regressão (hipótese 5Tabela 1). A segunda propõe que quanto maior a abundância de uma espécie maior a capacidade competitiva e menor a capacidade de colonização e, portanto, maior o risco de extinção, resultando em uma inclinação positiva da reta da regressão (hipótese 6- Tabela 1).

E) Os valores esperados da variável dependente risco de extinção são uma função linear da variável independente amplitude de nicho. A este modelo matemático está associada uma hipótese proposta na literatura, que propõe quanto maior a amplitude de nicho menor o risco de extinção, resultando em uma inclinação negativa da reta da regressão (hipótese 7- Tabela 1).

F) Os valores esperados da variável dependente risco de extinção são uma função linear das variáveis abundância local e amplitude de nicho. Esse modelo agrupa três hipóteses anteriormente mencionadas sobre os efeitos destas duas variáveis sobre o risco de extinção, e assume que há um efeito aditivo das mesmas sobre o risco de extinção. 
G) Os valores esperados da variável dependente risco de extinção são uma função linear das variáveis independentes abundância local e amplitude de nicho, sendo que o efeito de uma depende da outra. Esse modelo agrupa três hipóteses anteriormente mencionadas sobre os efeitos destas duas variáveis sobre risco de extinção local, e assume que há interação entre elas na definição do risco de extinção local.

A construção e seleção dos modelos foram realizadas no ambiente computacional R (R, 2010). 


\section{RESULTADOS}

\section{Espécies de pequenos mamíferos}

Durante as 21 sessões de amostragem na Reserva Florestal do Morro Grande, foram capturados 1343 indivíduos de 24 espécies de pequenos mamíferos (16 espécies de roedores e oito espécies de marsupiais) (Tabela 2). Como mencionado anteriormente, três duplas de espécies do mesmo gênero (Juliomys pictipes e J. ossitenuis, Monodelphis scalops e M. americana, e Phyllomys nigrispinus e $P$. sulinus) foram consideradas conjuntamente nas análises de dados devido sua morfologia externa críptica. Assim, foram consideradas 21 espécies ou pares de espécies neste trabalho.

\section{Risco de extinção local, abundância local, capacidade de dispersão e amplitude de nicho}

O índice de risco de extinção variou de $-0,217$ a $+0,820$ entre as 21 espécies de pequenos mamíferos (Tabela 3). As três espécies com os maiores valores de risco de extinção local foram Euryoryzomys russatus, Monodelphis iheringi e Juliomys spp., e as três espécies com os menores valores de risco de extinção foram Akodon montensis, Gracilinanus microtarsus e Sooretamys angouya (Tabela 3).

Foram obtidas 87 estimativas de abundância local através do CAPTURE para um total de nove espécies (Anexo 1). Estas estimativas estiveram positivamente correlacionadas aos valores de abundância local calculados através do MNKA ( $\mathrm{r}=0,9779, \mathrm{p}<0.001$; Anexo 2). Como esperado, comparando-se as medianas entre as sessões de amostragem da abundância local das nove espécies de pequenos mamíferos entre os dois métodos (CAPTURE e MNKA), os valores foram mais altos nas estimativas do CAPTURE, que considera a probabilidade de captura (exceto para Oligoryzomys nigripes, Tabela 4). As espécies mais abundantes, e que foram incluídas na primeira seleção de modelos, foram os roedores Akodon montensis, Delomys sublineatus, Oligoryzomys nigripes, Thaptomys nigrita, Euryoryzomys russatus, Brucepattersonius soricinus e o marsupial Marmosops incanus. Entre estas sete espécies, a mediana da abundância local em 6 ha variou de 6 a 32,5 indivíduos pelas estimativas do CAPTURE e de 5 a 26 indivíduos pelo cálculo do MNKA (Tabela 4).

Para estas mesmas sete espécies, foi possível estimar o tamanho da área de vida através do MPC (com pelo menos quatro pontos de captura), embora para três delas a estimativa foi possível apenas para poucos indivíduos (Tabela 5). As estimativas de área de vida e a distância máxima percorrida entre sessões sucessivas, para 77 indivíduos destas sete espécies, foram correlacionadas positivamente $(r=0,6876 ; p<0,001)$ (Anexo 5). Esta correlação indica que a 
distância máxima percorrida entre sessões pode ser utilizada como um índice da estimativa de área de vida, assim representando um índice da capacidade de dispersão das espécies de pequenos mamíferos. Entre estas sete espécies, a mediana (entre os indivíduos da espécie) da área de vida variou de 200 a $1600 \mathrm{~m}^{2}$ e a mediana da distância máxima percorrida entre sessões sucessivas variou de 10 a 101,98 m (Tabela 5).

Ao realizar os ajustes de distribuições teóricas aos valores de distância máxima percorrida entre sessões de amostragem sucessivas para cada uma das sete espécies, a distribuição gamma foi a que melhor se ajustou aos dados de cinco espécies (Anexo 6 e 7). Para O. nigripes, a distribuição que melhor se ajustou aos dados foi a normal, e para $M$. incanus, a distribuição lognormal (Anexos 6 e 7). O quantil 0,90 das distribuições melhor ajustadas variou de 78,98 a 122,18 m entre as sete espécies (Tabela 5).

Das 21 espécies ou pares de espécies de pequenos mamíferos capturadas na Reserva Florestal do Morro Grande, 11 apresentam alta especialização no habitat "florestas nativas", três média especialização, três baixa especialização e uma não é especializada neste habitat (Tabela 6). As espécies Marmosa paraguayana, Nectomys squamipes e Blarinomys breviceps não puderam ser classificadas quanto a sua amplitude de nicho, devido à falta de dados (Rossi, 2011).

\section{Modelos sobre os determinantes ecológicos do risco de extinção local}

A primeira seleção de modelos considerou sete espécies de pequenos mamíferos, para as quais foi possível obter, além da abundância local e da amplitude de nicho, os valores de capacidade de dispersão. Para estas sete espécies, todas as correlações entre as variáveis independentes foram não significativas (amplitude de nicho e abundância local: $\mathrm{p}=0,0698, \mathrm{r}=$ 0,7169; amplitude de nicho e capacidade de dispersão: $\mathrm{p}=0,6867, \mathrm{r}=-0,1878$; abundância local e capacidade de dispersão: $\mathrm{p}=0,3842, \mathrm{r}=-0,3921)$, indicando independência entre elas.

Nesta primeira seleção de modelos, dois modelos foram selecionados (Tabela 7, Figura 3): o modelo nulo (modelo A) e o modelo contendo a variável independente amplitude de nicho (modelo E). Assim, a seleção de modelos indica que o risco de extinção das espécies de pequenos mamíferos é menor entre as espécies com maior amplitude de nicho (Figura 3), como esperado pela hipótese 7 (Tabela 1). Os outros três modelos (modelos B a D), sendo dois contendo a variável capacidade de dispersão e um contendo a variável abundância local, foram menos plausíveis (Tabela 7, Figura 3). Os modelos B e D indicam que o risco de extinção diminui com o aumento da abundância local (hipótese 5 - Tabela 1; Figura 3) e aumenta com o aumento da capacidade de dispersão (hipótese 2 - Tabela 1; Figura 3). O modelo C indica que o 
risco de extinção é menor nas espécies com capacidade de dispersão intermediária, ao contrário do proposto na literatura (hipótese 4 - Tabela 1; Figura 3). O uso dos quantis 0,85 ou 0,95 da distribuição teórica melhor ajustada aos dados de distância máxima percorrida para representar a capacidade de dispersão das espécies não altera os modelos selecionados nesta primeira seleção de modelos (Anexo 8).

A segunda seleção de modelos considerou 18 espécies de pequenos mamíferos. Para estas 18 espécies, novamente não houve correlação entre as variáveis amplitude de nicho e abundância local $(\mathrm{p}=0,5515, \mathrm{r}=-0,15035)$. O modelo contendo apenas a variável independente amplitude de nicho (modelo E) foi o mais plausível e único selecionado (Tabela 8; Figura 3), e indica que o risco de extinção diminui com o aumento da amplitude de nicho, como proposto pela hipótese 7 (Tabela 1).

Os modelos de regressão linear múltipla aditivo e de interação (modelos F e G), apesar de menos plausíveis, foram melhores do que o nulo, enquanto que o modelo contendo apenas a abundância local foi o pior modelo, sendo o único menos plausível que o nulo (Tabela 8; Figura 4). No modelo aditivo, o risco de extinção diminui com o aumento da amplitude de nicho e aumenta com o aumento da abundância local, conforme hipóteses 6 e 7 (Tabela 1). No entanto, o coeficiente positivo da abundância local foi bastante baixo e próximo de zero (0.003) neste modelo (Tabela 8). No modelo de interação, novamente o risco de extinção diminui com o aumento da amplitude de nicho e aumenta com o aumento da abundância, mas o efeito positivo da abundância sobre o risco de extinção diminui quando a amplitude de nicho é maior. Neste modelo que inclui a interação, o coeficiente da abundância local foi um pouco mais elevado (0.031, Tabela 8). Já no pior modelo, aquele que contém apenas a abundância local, o risco de extinção diminui com o aumento da abundância, mas novamente o coeficiente foi muito próximo de zero $(-0.001$, Tabela 8$)$. 


\section{DISCUSSÃO}

\section{Espécies de pequenos mamíferos}

Ao longo das 21 sessões de amostragem foi possível capturar 24 das 30 espécies de pequenos mamíferos já registradas na Reserva Florestal do Morro Grande (Pardini e Umetsu, 2006; Pinotti, 2010). Essas 24 espécies representam 56\% do total de 43 espécies de pequenos mamíferos capturadas nos 104 sítios de amostragem no Planalto Atlântico Paulista (Pardini et al. 2010; Umetsu 2010). O grande número de espécies capturado neste trabalho é reflexo do elevado esforço amostral, tanto temporal como espacial, representado pelo tamanho e número das grades e número de armadilhas, e o número de dias e sessões de amostragem. Poucos trabalhos com pequenos mamíferos na Mata Atlântica capturaram um número tão alto de espécies (mas, veja Pardini, 2004; Passamani e Fernandez, 2011).

\section{Índice de risco de extinção}

Diferentes índices de risco de extinção associado à fragmentação têm sido propostos na literatura (e.g. Bolger et al., 1991; Davies et al., 2000; Thornton et al., 2011). O mais simples destes considera apenas o número de fragmentos florestais com a ocorrência da espécie de um total de fragmentos amostrados (Bolger et al., 1991). Este índice assume que as espécies capturadas distribuem-se de maneira homogênea em toda a área de estudo antes da fragmentação, e que a probabilidade de registrar as espécies nos fragmentos independe da abundância das mesmas. Essas premissas, no entanto, são pouco plausíveis, pois geralmente espécies mais abundantes têm maior chance de serem capturadas (Gaston, 1994). Além disso, há variações na abundância de uma espécie dada a heterogeneidade ambiental mesmo em florestas contínuas (Brown, 1984; Gaston e Blackburn, 2000).

Outros índices mais complexos procuram minimizar estes problemas. Davies e colaboradores (2000), a partir de dados de abundância em sítios de área contínua e em área fragmentada, propuseram um índice que inclui um fator de correção (i.e., abundância das espécies dois anos antes da fragmentação) para remover o efeito de distribuição desigual antes da fragmentação. $\mathrm{O}$ índice que utilizamos considera o número de sítios com ocorrência da espécie,

ao invés da abundância, e contabiliza sítios em área contínua e fragmentada. É semelhante ao índice utilizado por Thornton e colaboradores (2011), que também considerou o número de sítios ocupados pelas espécies em áreas contínuas e fragmentadas, porém através da probabilidade de ocupação desses sítios. Este tipo de índice que leva em conta a ocorrência observada ou estimativas de ocupação também deve ser menos afetado pelas variações na forma de 
distribuição (homogênea ou heterogênea) e na abundância entre as espécies. Além disso, ter considerado três regiões e seis paisagens para o cálculo do índice de risco de extinção possivelmente o tornou menos enviesado, não só pelo aumento do número de sítios amostrados, mas também por permitir a incorporação de variações geográficas na forma de distribuição e abundância das espécies.

\section{Abundância local, capacidade de dispersão e amplitude de nicho}

\section{Abundância local}

Do total de 21 espécies ou pares de espécies de pequenos mamíferos capturadas na Reserva Florestal do Morro Grande, mais da metade (12) apresentaram abundância local baixa, sem indivíduos capturados em mais da metade das sessões de amostragem. A presença de muitas espécies raras e poucas espécies abundantes em uma comunidade biológica é um padrão recorrentemente observado, principalmente nos trópicos (Yu e Dobson, 2000; McGill et al., 2007). Nossos resultados indicam que a dificuldade em se estimar parâmetros populacionais e de uso do espaço é grande para a maior parte das espécies tropicais, mesmo quando o esforço amostral é elevado como o realizado neste trabalho. O desenvolvimento e teste de índices destes parâmetros são, por consequiência, extremamente valiosos.

As espécies mais abundantes e as mais raras em nossas grades de captura também o foram em outros trabalhos realizados no Planalto Atlântico Paulista (Bueno, 2008; Püttker et al., 2008a; Pinotti et al., 2011). Para a maioria das espécies, até mesmo para algumas espécies relativamente abundantes em nossa área (e.g. Thaptomys nigrita, Monodelphis spp., B. soricinus), há poucos dados disponíveis sobre densidade populacional, seja na Mata Atlântica, seja em toda sua área de ocorrência (Rossi, 2011). Entre as espécies com este tipo de informação disponível para áreas de Mata Atlântica, duas parecem ser mais abundantes em outras regiões de mata contínua do que na Reserva Florestal do Morro Grande. O roedor B. breviceps, que teve baixas densidades populacionais médias na nossa área de estudo (de zero, 0,02 e 0,02 indivíduos/ha) parece ser mais comum ao norte da Mata Atlântica, como no Estado da Bahia (Pardini, 2001). O marsupial M. paulensis, para o qual obtivemos um total de oito indivíduos capturados ao longo dos 21 meses de amostragem, foi mais abundante em uma área contínua de Mata Atlântica ao sul do Planalto, onde ao longo de dois anos de amostragem, em uma grade de armadilhas de 2,8 ha, foram capturados um total de 51 indivíduos (Leiner et al., 2008). Para outras espécies raras capturadas na Reserva, informações de densidades estão disponíveis apenas para fragmentos florestais. O marsupial $M$. paraguayana teve densidades populacionais médias variando de 1,01 a 1,86 indivíduos/ha em fragmentos florestais em zonas de baixada do Rio de 
Janeiro (Quental et al., 2001; Barros, 2006), enquanto em nossas áreas do Planalto a densidade média foi bem mais baixa (0,02, 0,07 e 0,07 indivíduos/ha).

Entre as espécies mais abundantes na Reserva Florestal do Morro Grande, a densidade populacional média do roedor A. montensis (a espécie com maior densidade populacional, com 2,36, 3,36 e 8,88 indivíduos/ha) foi em parte das grades semelhante ao observado em anos anteriores na Reserva (4,06 indivíduos/ha; Püttker et al., 2008a) e em uma área de Mata Atlântica em Santa Catarina (3,3 indivíduos/ha; Graipel et al., 2006). Em uma de nossas grades, a densidade média foi mais elevada e comparável ao valor encontrado em fragmentos florestais de tamanho médio (30 ha) no Planalto (8,92 indivíduos/ha e 8,63 indivíduos/ha; Püttker et al., 2008a). A densidade populacional média do roedor $O$. nigripes (2,43, 2,81 e 3,43 indivíduos/ha), também foi maior do que em anos anteriores na Reserva (0.72 indivíduos/ha; Püttker et al., 2008a), e mais semelhante às encontradas em fragmentos florestais de tamanho médio (30 ha) no Planalto (2,93 e 2,35 indivíduos/ha; Püttker et al., 2008a). Já a densidade populacional média do roedor D. sublineatus $(1,45,3,00$ e 3,45 indivíduos/ha) foi semelhante à observada na Reserva em anos anteriores (2,96 indivíduos/ha; Püttker et al., 2008a), e bem superiores aos valores encontrados em fragmentos florestais de tamanho médio (30 ha) no Planalto (0,37 e 0,38 indivíduos/ha; Püttker et al. 2008a). A densidade populacional média do roedor E. russatus $(1,79,2,02$ e 2,24 indivíduos/ha) foi semelhante à observada em uma área de Mata Atlântica de Santa Catarina (2,7 ind/ha; Graipel et al., 2006), mas menor do que em áreas de baixada no Estado de São Paulo (5,26 indivíduos/ha; Bergallo, 1994).

Para a maioria das espécies de pequenos mamíferos, estimativas precisas de abundância que considerem a probabilidade de captura não são possíveis, mesmo quando se utilizada grandes grades, com dois tipos de armadilhas, o que aumenta as chances de captura (Umetsu et al., 2006). Porém, os dados deste estudo demonstram que o MNKA é um bom índice de abundância, que captura as diferenças relativas entre as espécies, como observado em outros estudos (Gentile e Fernandez, 1999; Quental et al., 2001). Quando há necessidade de dados acurados de abundância, como em trabalhos de demografia, os pesquisadores podem fazer uso de um fator de correção sobre o valor de MNKA (e.g. Gentile e Fernandez, 1999; Quental et al., 2001). No entanto, em muitos trabalhos como o nosso, em que o objetivo é a comparação entre espécies, essa correção não é necessária (e.g. Passamani, 2000; Mabry et al., 2003; Dalmagro e Vieira, 2005; Püttker et al., 2008a). 


\section{Área de vida, distância máxima percorrida e capacidade de dispersão}

A maioria dos trabalhos disponíveis na literatura, que estimaram a área de vida para pequenos mamíferos através do mínimo polígono convexo, considerou pontos entre capturas sucessivas dentro de uma mesma sessão de amostragem. Mesmo assim, não houve diferenças muito elevadas entre as estimativas de área de vida obtidas nestes trabalhos e as estimativas que obtivemos na Reserva Florestal do Morro Grande. Das sete espécies para as quais foi possível obter estimativas acuradas de área de vida, para quatro (M. incanus, $O$. nigripes, $B$. soricinus e $T$. nigrita) não há na literatura outros valores disponíveis. Para o gênero Akodon, foram encontrados trabalhos apenas com a espécie $A$. cursor. A média da área de vida obtida para esta espécie foi $2800 \mathrm{~m}^{2}$ (Gentile et al., 1997) e $1800 \mathrm{~m}^{2}$ (Fernandez 1989), muito maiores que a mediana da área de vida de A. montensis obtida neste trabalho $\left(750 \mathrm{~m}^{2}\right)$, apesar do valor máximo obtido ter sido bem superior nos nossos dados $\left(6900 \mathrm{~m}^{2}\right)$. A média da área de vida para a espécie $E$. russatus em uma área contínua de Mata Atlântica no Rio de Janeiro foi de 798,32 $\mathrm{m}^{2}$ (Bergallo e Magnusson, 2004), menor que a mediana obtida neste trabalho $\left(1100 \mathrm{~m}^{2}\right)$. Porém, os valores máximos e mínimos dos nossos dados $\left(2400 \mathrm{~m}^{2}\right.$ e $\left.200 \mathrm{~m}^{2}\right)$ foram muito semelhantes $\left(2500 \mathrm{~m}^{2} \mathrm{e}\right.$ $200 \mathrm{~m}^{2}$; Bergallo e Magnusson, 2004).

Apesar da grande quantidade de estudos sobre área de vida nos trópicos, especialmente para pequenos mamíferos (Prevedello et al., 2008), a maioria desses estudos violaram a premissa de independência temporal entre capturas, e utilizaram pontos de captura registrados em curto período de tempo. Mesmo assim, apresentam a estimativa de área de vida para poucos indivíduos, e geralmente para as espécies mais abundantes (Prevedello et al., 2008). As estimativas de área de vida neste trabalho mantiveram a independência temporal, o que por sua vez ocasionou um tamanho amostral baixo de pontos de captura. As espécies menos abundantes não tiveram número de capturas suficientes para se estimar a área de vida, nem mesmo ao se utilizar grades de armadilhas grandes como as nossas. Assim, é importante que outras métricas que representem o uso do espaço das espécies sejam desenvolvidas e testadas, já que requerem um menor número de recapturas.

Diferentes medidas de distâncias foram propostas como índice da área de vida (Stickel, 1954; Koeppl et al., 1977; Slade e Russell, 1998). Medidas de distâncias obtidas em grades de armadilhas e freqüentemente utilizadas como índices da estimativa de área de vida são distâncias percorridas entre capturas sucessivas (Koeppl et al., 1977; Slade e Russell, 1998; Püttker et al., no prelo), distância entre todos os pontos de captura (Koeppl et al., 1977; Püttker et al., no prelo) e máxima distância entre todos os pontos de captura de um indivíduo (Stickel, 1954; Püttker et 
$a l$, no prelo). No entanto, poucos foram os trabalhos que avaliaram qual o melhor índice a ser utilizado para espécies tropicais (e.g. Püttker et al., no prelo).

Entre essas medidas de distância, a máxima distância percorrida entre capturas sucessivas em uma mesma sessão de amostragem é uma medida freqüentemente utilizada em trabalhos que comparam o deslocamento entre indivíduos de sexos diferentes (Bergallo e Magnusson, 2004; Gomez et al., 2010) e entre diferentes espécies (Bergallo e Magnusson, 2004), e é bastante semelhante à medida de distância utilizada em nosso trabalho (distância máxima percorrida entre sessões de amostragem sucessivas). Há, no entanto, vantagens da medida que utilizamos em relação às medidas de distância percorrida obtidas dentro de uma mesma sessão de amostragem. Uma vantagem é a possibilidade de se detectar maiores distâncias percorridas, já que foi mantida a independência temporal entre as capturas. Para essas distâncias máximas entre sessões sucessivas, não há a influência e interferência das outras armadilhas presentes na grade, que geralmente barram o deslocamento do indivíduo entre as capturas sucessivas dentro de uma mesma sessão de amostragem, resultando em uma medida de distância subestimada. Além disso, a distância máxima entre sessões sucessivas que utilizamos foi capaz de capturar as diferenças relativas no tamanho das áreas de vida entre as espécies, o que indica que seja um bom índice da área de vida.

É importante notar, entretanto, que os valores obtidos para os quantis das distribuições que melhor se ajustaram aos dados de distância máxima percorrida entre sessões sucessivas variaram pouco entre as espécies de pequenos mamíferos. Isto indica que os requerimentos de área e as capacidades de dispersão não variam grandemente dentro deste grupo de espécies.

\section{Amplitude de nicho}

A amplitude de nicho de uma espécie pode ser descrita a partir de diferentes características de sua história natural (características intrínsecas), das características do ambiente que utiliza ou habita (características extrínsecas) ou conciliando ambas as abordagens (Pulliam, 2000; Devictor et al., 2010). Idealmente, quanto mais informações sobre a história natural de uma espécie, melhor a caracterização do nicho, já que este, pela definição de Hutchinson (1957 apud Brown, 1984), é multidimensional. Neste trabalho, a estimativa de amplitude de nicho foi baseada em características extrínsecas do habitat, que é a informação mais refinada e comparativa disponível para as espécies de pequenos mamíferos na Mata Atlântica. Os requerimentos de habitat parecem variar bastante entre as espécies deste grupo de mamíferos, com assembléias bem distintas entre áreas abertas e florestadas (Umetsu e Pardini 2007; Naxara 2008). 
Para o grupo de espécies de pequenos mamíferos abordado neste trabalho, a classificação de amplitude de nicho utilizada é consistente com outras informações disponíveis na literatura. De modo geral, espécies generalistas capazes de ocupar os dois ambientes (florestado e alterado) são espécies que preferem as bordas de remanescentes florestais (Naxara, 2008), usam microhabitats associados a matas perturbadas (Püttker et al., 2008b) e são mais comuns em matas em estágios mais iniciais de regeneração (Pinotti, 2010). Essas diferenças de requerimento de habitat parecem estar associadas à maior plasticidade fisiológica (Ariovaldo Neto, dados não publicados), já que uma das principais mudanças nestes ambientes alterados em relação às florestas bem preservadas são as condições microclimáticas (Kędziora e Olejnik, 2002; Laurance, 2004).

\section{Determinantes do risco de extinção}

As diferentes hipóteses concorrentes consideradas nesse trabalho seguiram trabalhos teóricos e empíricos, que em seu conjunto sugerem que os mecanismos ou o sentido da influência de certos atributos ecológicos das espécies sobre o risco de extinção local podem variar. Ambas as seleções de modelo realizadas neste trabalho indicam que a amplitude de nicho é fundamental para determinar o risco de extinção local. De fato, a amplitude de nicho é um dos poucos atributos ecológicos em que encontramos um só sentido e mecanismo para seu efeito sobre o risco de extinção na literatura: espécies especialistas são menos plásticas quanto à fisiologia, comportamento ou ecologia, e assim mais sensíveis a distúrbios.

Esse resultado é coerente com uma série de trabalhos empíricos mais recentes que indicam que o grau de especialização é um atributo fundamental para a resposta das espécies a perturbações (Purvis et al., 2000b; Mabry et al. 2003; Swihart et al., 2003; Manor e Saltz, 2008; Umetsu et al., 2008; Pardini et al., 2010; Öckinger et al., 2010). Trabalhos que não obtiveram este resultado (e.g. Owens e Bennet, 2000) podem ter medido um aspecto do nicho que não esteve relacionado diretamente ao tipo de perturbação (Gaston et al., 1997; Gaston e Blackburn, 2000; Purvis et al., 2000). É fundamental observar o fator causal da extinção (que, em nosso trabalho, foi a fragmentação do habitat) para estabelecer quais os aspectos do nicho podem ser determinantes da extinção local (Purvis et al., 2000).

Nosso resultado também é coerente com outros trabalhos empíricos sobre a vulnerabilidade a fragmentação do habitat em pequenos mamíferos, que avaliaram o efeito de métricas relacionadas à capacidade das espécies de usar ou se deslocar pelos ambientes alterados do entorno, embora não tenham chamado essas métricas de amplitude de nicho (e.g. Laurance, 1990, 1991, 1994; Pires et al., 2002; Mabry et al., 2003; Viveiros de Castro e Fernandez, 2004). 
Assim, os ambientes alterados no entorno de fragmentos podem funcionar como habitat para algumas espécies, e não apenas uma barreira ou não-habitat (McIntyre e Hobbs, 1999), dependendo da qualidade e da estrutura desses ambientes (Szacki e Liro, 1991; Kupfer et al., 2006; Umetsu et al., 2008; Prevedello e Vieira, 2010). Dessa maneira, a habilidade de utilizar diferentes ambientes como habitat (característica de espécies generalistas) determina um menor risco de extinção em paisagens fragmentadas (Andrén et al., 1997; Fisher et al., 2003; Mabry et al., 2003; Umetsu et al., 2008; Pardini et al. 2010).

Por outro lado, a capacidade de dispersão não foi uma característica previsora do risco de extinção local, provavelmente porque essa característica variou pouco entre as espécies de pequenos mamíferos. No entanto, dada à baixa vagilidade dessas espécies de pequeno porte, a capacidade de ocupar ambientes alterados deve ser muito mais importante para definir o fluxo de indivíduos e genes entre sub-populações do que o deslocamento de indivíduos entre manchas de habitat. Além disso, comparações das distâncias percorridas e das frequiências de deslocamentos entre áreas contínuas e entre fragmentos indicam que espécies de pequenos mamíferos evitam atravessar ambientes alterados, mesmo que as distâncias a serem percorridas estejam dentro de suas capacidades de dispersão (Diffendorfer et al., 1995). Por fim, é possível que espécies que percorrem maiores distâncias tenham tanto vantagens como desvantagens, como indicam as várias hipóteses concorrentes sobre o efeito da capacidade de dispersão sobre o risco de extinção local (Travis e Dytham 1999; Thomas, 2000; Hanski e Ovaskainen, 2003) e como verificado em alguns trabalhos empíricos (Diffendorfer et al., 1995; Thomas 2000).

É possível, no entanto, que a capacidade de dispersão seja um atributo mais importante para o risco de extinção local em outros grupos em que a capacidade de dispersão seja maior ou mais variável. Por exemplo, as aves possuem um maior potencial de dispersão em relação aos mamíferos (Gaston et al., 2007) e o efeito das diferenças na capacidade de dispersão se mostrou importante para determinar a ocorrência e persistência de aves do sub-bosque em manchas de habitat remanescente (Moore et al., 2008). No entanto, analisar somente a capacidade de dispersão de uma espécie sem considerar demandas conflitantes com outros atributos ecológicos não é adequado (Burton et al., 2010).

A abundância local em áreas contínuas, considerada isoladamente de outros atributos ecológicos, não foi determinante do risco de extinção para as espécies de pequenos mamíferos analisadas no nosso trabalho, assim como observado em outros estudos empíricos com pequenos mamíferos (Laurance, 1991, 1994; Viveiro de Castro e Fernandez, 2004) e como sugerido em trabalhos teóricos (Andrén et al., 1997). No entanto, em outros trabalhos empíricos com pequenos mamíferos (Bolger et al., 1997), aves (Bolger et al., 1991) e besouros (Davies et al., 
2000) em áreas fragmentadas, a elevada abundância local antes da fragmentação foi um fator determinante para diminuir o risco de extinção.

A abundância local só foi importante para explicar as diferenças no risco de extinção entre as espécies de pequenos mamíferos estudadas quando considerada junto com a amplitude de nicho e levando-se em consideração a interação entre as duas variáveis. Outros trabalhos empíricos observaram que a menor abundância local antes da fragmentação foi uma das características determinantes do maior risco de extinção, porém não o mais importante (Laurance, 1991; Purvis et al. 2000a). De fato, padrões tendem a emergir quando se considera mais de um atributo ecológico para avaliar o risco de extinção (Swihart et al., 2003; Watling e Donnelly, 2007).

No entanto, entre as espécies que estudamos o efeito da abundância local sobre o risco de extinção foi positivo, ao contrário do que sugerem muitos trabalhos empíricos e teóricos. Este resultado é consistente com a idéia de que a abundância local indica o grau de especialização e a capacidade competitiva das espécies (Rabinowitz et al., 1984; Glazier e Eckert, 2002), sendo que as espécies mais abundantes seriam as menos capazes de suportar mudanças no ambiente (Tilman, 1994), ou com menor capacidade de colonização (Tilman, 1994; Cadotte et al., 2006). A interação com a amplitude de nicho, entretanto, indica que este efeito positivo da abundância sobre o risco de extinção só ocorre ou é mais forte entre as espécies com menor amplitude de nicho, as mais especializadas. Assim, entre estas espécies que não são capazes de ocupar os ambientes alterados, o risco de extinção parece ser também definido pela sua baixa capacidade de colonização, que pode ser dada tanto pela baixa capacidade de dispersão como pela baixa taxa de crescimento populacional (Gaston 1994; Tilman, 1994; Cadotte et al., 2006; Burton et al., 2010), também associada ao risco de extinção (Purvis et al., 2000a). Como entre as espécies estudadas a capacidade de dispersão varia pouco e parece não ser importante, os resultados sugerem que o risco de extinção das espécies de pequenos mamíferos especialistas de habitat seja secundariamente definido pela capacidade de crescimento populacional, que seria maior em espécies com menor capacidade competitiva e assim menos abundantes localmente. 


\section{REFERÊNCIAS BIBLIOGRÁFICAS}

Amarasekare, P., e R. M. Nisbet. 2001. Spatial heterogeneity, source-sink dynamics, and the local coexistence of competing species. American Naturalist 158:572-584.

Andrén, H. 1994. Effects of habitat fragmentation on birds and mammals in landscapes with different proportions of suitable habitat: a review. Oikos 71:355-366.

Andrén, H., A. Delin, e A. Seiler. 1997. Population response to landscape changes depends on specialization to different landscape elements. Oikos 80:193-196.

Barnosky, A. D., N. Matzke, S. Tomiya, G. O. U. Wogan, B. Swartz, T. B. Quental, C. Marshall, J. L. McGuire, E. L. Lindsey, K. C. Maguire, B. Mersey, e E. A. Ferrer. 2011. Has the earth's sixth mass extinction already arrived. Nature 471:51-57.

Barros, C. S. 2006. Como pequenas populações persistem em paisagens fragmentadas? Onze anos de estudo de populações do marsupial Micoureus demerarae em fragmentos de Mata Atlântica no Estado do Rio de Janeiro. Dissertação (Mestrado entregue à Universidade Federal do Rio de Janeiro.

Bergallo, H. 1994. Ecology of a small mammal community in an Atlantic rain forest area in southeastern Brazil. Studies on Neotropical Fauna and Environment 29:197-217.

Bergallo, H. G., e W. E. Magnusson. 2004. Factors affecting the use of space by two rodent species in Brazilian Atlantic Forest. Mammalia 68:121-132.

Beyer, H. L. 2004. Hawth's Analysis Tools for ArcGIS, version Version 3.27.

Bolger, D. T., A. C. Alberts, e M. E. Soule. 1991. Occurrence patterns of bird species in habitat fragments - sampling, extinction, and nested species subsets. American Naturalist 137:155-166.

Bolger, D. T., A. C. Alberts, R. M. Sauvajot, P. Potenza, C. McCalvin, D. Tran, S. Mazzoni, e M. E. Soule. 1997. Response of rodents to habitat fragmentation in coastal southern California. Ecological Applications 7:552-563.

Börger, L., N. Franconi, G. De Michele, A. Gantz, F. Meschi, A. Manica, S. Lovari, e T. Coulson. 2006. Effects of sampling regime on the mean and variance of home range size estimates. Journal of Animal Ecology 75:1393-1405.

Bowman, J., J. A. G. Jaeger, e L. Fahrig. 2002. Dispersal distance of mammals is proportional to home range size. Ecology 83:2049-2055.

Brown, J. H. 1984. On the relationship between abundance and distribution of species. American Naturalist 124:255-279.

Brown, J. H., e A. Kodric-Brown. 1977. Turnover rates in insular biogeography: effect of immigration on extinction. Ecology 58:445-449.

Brown, J. H., e M. V. Lomolino. 2006. Biogeografia FUNPEC, Ribeirão Preto.

Bueno, A. A. 2008. Pequenos mamíferos da Mata Atlântica do planalto atlântico paulista: uma avaliação da ameaça de extinção e da resposta a alterações no contexto e tamanho dos remanescentes. Tese (Doutorado em Zoologia), Universidade de São Paulo, São Paulo.

Burnham, K. P., e D. R. Anderson. 2002. Model selection and multimodel inference - a practical information-theoretic approach, second edition edition. Springer Science + Business Media, New York, USA.

Burton, O. J., B. L. Phillips, e J. M. Travis. 2010. Trade-offs and the evolution of life-histories during range expansion. Ecology Letters 13:1210-1220.

Cadotte, M. W., D. V. Mai, S. Jantz, M. D. Collins, M. Keele, e J. A. Drake. 2006. On testing the competition-colonization trade-off in a multispecies assemblage. The American Naturalist 168: 704- 709. 
Clavel, J., R. Julliard, e V. Devictor. 2010. Worldwide decline of specialist species: toward a global functional homogenization? Frontiers in Ecology and the Environment doi:10.1890/080216.

Dalmagro, A. D., e E. M. Vieira. 2005. Patterns of habitat utilization of small rodents in an area of Araucaria forest in Southern Brazil. Austral Ecology 30:353-362.

Davies, K. F., C. R. Margules, e K. F. Lawrence. 2000. Which traits of species predict population declines in experimental forest fragments? Ecology 81:1450-1461.

Devictor, V., J. Clavel, R. Julliard, S. Lavergne, D. Mouillot, W. Thuiller, P. Venail, S. Villeger, e N. Mouquet. 2010. Defining and measuring ecological specialization. Journal of Applied Ecology 47:15-25.

Diffendorfer, J. E., M. S. Gaines, e R. D. Holt. 1995. Habitat fragmentation and movements of three small mammals (Sigmodon, Microtus, and Peromyscus). Ecology 76:827-839.

ESRI. 1999-2006. ArcGIS 9.2, version 9.2. Environmental Systems Resource Institute.

Ewers, R. M., e R. K. Didham. 2006. Confounding factors in the detection of species responses to habitat fragmentation. Biological Reviews 81:117-142.

Fahrig, L. 2002. Effect of habitat fragmentation on the extinction threshold: a synthesis. Ecological Applications 12:346-353.

Fahrig, L. 2003. Effects of habitat fragmentation on biodiversity. Annual Review of Ecology, Evolution and Systematic 34:487-515.

Fernandez, F. A. S. 1989. Dinâmica de populações e uso do espaço e do tempo em uma comunidade de pequenos mamíferos na restinga de Barra de Maricá, Rio de Janeiro. Dissertação (Mestrado em Ecologia), Universidade Estadual de Campinas, Campinas.

Fisher, D. O., S. P. Blomberg, e I. P. F. Owens. 2003. Extrinsic versus intrinsic factors in the decline and extinction of Australian marsupials. Proceedings of the Royal Society BBiological Sciences 270:1801-1808.

Fonseca, G. A. B., G. Herrmann, Y. L. R. Leite, R. A. Mittermeier, A. B. Rylands, e J. L. Patton. 1996. Lista anotada dos mamíferos do Brasil. Occasional Papers in Conservation Biology $4: 1-38$

Gaston, K. J., T. M. Blackburn e J. H. Lawton. 1997. Interspecific abundance-range size relationships: an appraisal of mechanisms. Journal of Animal Ecology 66: 579-601.

Gaston, K. J. 1994. Rarity. Chapman \& Hall, Londres.

Gaston, K. J., e R. A. Fuller. 2007. Biodiversity and extinction: losing the common and the widespread. Progress in Physical Geography 31:213-225.

Gaston, K. J., e T. M. Blackburn. 2000. Pattern and Process in Macroecology. Blackwell Publishing, Londres.

Gentile, R., e F. A. S. Fernandez. 1999. A field comparison of two capture-mark-recapture estimators of small mammal populations. Revista Brasileira de Zoologia 16:1109-1114.

Gentile, R., P. S. D’Andrea, e R. Cerqueira. 1997. Home ranges of Philander frenata and Akodon cursor in a brazilian restinga (coastal shrubland). Mastozoologia Neotropical 4:105-112.

Glazier, D. S., e S. E. Eckert. 2002. Competitive ability, body size and geographical range size in small mammals. Journal of Biogeography 29:81-92.

Gomez, D., L. Sommaro, A. Steinmann, M. Chiapper, e J. Priotto. 2010. Movement distances of two species of sympatric rodents in linear habitats of Central Argentine agro-ecosystems. Mammalian Biology 76: 58-63.

Gotelli, N. J., e A. M. Ellison. 2004. A primer of ecological statistics. Sinauer Associates, Inc., Sunderland, Massachusetts.

Graipel, M. E., J. J. Cherem, E. L. A. Monteiro-Filho, e L. Glock. 2006. Dinâmica populacional de marsupiais e roedores no Parque Municipal da Lagoa do Peri, Ilha de Santa Catarina, sul do Brasil. Mastozoologia Neotropical 13:31-49. 
Haila, Y. 2002. A conceptual genealogy of fragmentation research: from island biogeography to landscape ecology. Ecological Applications 12:321-334.

Hanski, I., e O. Ovaskainen. 2003. Metapopulation theory for fragmented landscapes. Theoretical Population Biology 64:119-127.

Hartley, S., e W. E. Kunin. 2003. Scale dependency of rarity, extinction risk, and conservation priority. Conservation Biology 17:1559-1570.

Henle, K., K. F. Davies, M. Kleyer, C. Margules, e J. Settele. 2004. Predictors of species sensitivity to fragmentation. Biodiversity and Conservation 13:207-251.

Hobbs, N. T., e R. Hilborn. 2006. Alternatives to statistical hypothesis testing in ecology: A guide to self teaching. Ecological Applications 16:5-19.

Hutchinson, G.E. 1957. Population Studies- Animal ecology and demography- Concluding remarks. Cold Spring Harbor Symposium on Quantitative Biology 22: 415-427.

Ims, R. A., e H. P. Andreassen. 2005. Density-dependent dispersal and spatial population dynamics. Proceedings of the Royal Society B-Biological Sciences 272:913-918.

Isaac, J. L., J. Vanderwal, C. N. Johnson, e S. E. Williams. 2009. Resistance and resilience: quantifying relative extinction risk in a diverse assemblage of Australian tropical rainforest vertebrates. Diversity and Distributions 15:280-288.

Koeppl, J. W., N. A. Slade, e R. S. Hoffmann. 1977. Distance between observations as an index of average home range. The American Midland Naturalist 98:476-482.

Krebs, C. J. 1999. Ecological Methodology, segunda edição. Benjamin Cummings.

Kunin, W. E., e K. J. Gaston. 1993. The biology of rarity: patterns, causes and consequences. Trends in Ecology and Evolution 8:289-301.

Kupfer, J. A., G. P. Malanson, e S. B. Franklin. 2006. Not seeing the ocean for the islands: the mediating influence of matrix-based processes on forest fragmentation effects. Global Ecology and Biogeography 15:8-20.

Kędziora, A. e J. Olejnik. 2002.Water balance in agricultural landscape and options for its management by change in plant cover structure of landscape. Em Landscape Ecology in Agroecosystems Management, CRC Press.

Lande, R. 1998. Anthropogenic, ecological and genetic factors in extinction and conservation. Researches in Population Ecology 40:259-269.

Laurance, W. F. 1990. Comparative responses of five arboreal marsupials to tropical forest fragmentation. Journal of Mammalogy 71: 641-653.

Laurance, W. F. 1991. Ecological correlates of extinction proneness in australian tropical rain forest mammals. Conservation Biology 5:79-89.

Laurance, W. F. 1994. Rainforest fragmentation and the structure of small mammal communities in tropical Queensland. Biological Conservation 69:23-32.

Laurance, W. F. 2004. Forest-climate interactions in fragmented tropical landscapes. Philosophical Transactions of the Royal Society of London, Series B, Biological Sciences 359: 345-352.

Laver, P. N., e M. J. Kelly. 2008. A critical review of home range studies. Journal of Wildlife Management 72:290-298.

Leiner, N. O., E. Z. F. Setz, e W. R. Silva. 2008. Semelparity and factors affecting the reproductive activity of the Brazilian slender opossum (Marmosops paulensis) in southern Brazil. Journal of Mammalogy 89: 153-158.

Lira, P. K. 2005. Padrões espaciais de marsupiais em uma paisagem fragmentada de Mata Atlântica no Estado do Rio de Janeiro. 2005. Dissertação (Mestrado em Ecologia), Universidade Federal do Rio de Janeiro, Rio de Janeiro.

Mabry, K. E., E. A. Dreelin e G. W. Barrett. 2003. Influence of landscape elements on population and habitat use of small- mammal species. Journal of Mammalogy 84: 20-25. 
Mace, G. M., N. J. Collar, K. J. Gaston, C. Hilton-Taylor, H. R. Akcakaya, N. Leader-Williams, E. J. Milner-Gulland, e S. N. Stuart. 2008. Quantification of extinction risk: IUCN's system for classifying threatened species. Conservation Biology 22:1424-1442.

Macedo, J., D. Loretto, M. V. Vieira, e R. Cerqueira. 2006. Classes de desenvolvimento em marsupiais: um método para animais vivos. Mastozoología Neotropical 13:133-137.

Mandai, C. Y. 2010. Aplicação de modelos teóricos de distribuição de abundância das espécies na avaliação de efeitos de fragmentação sobre as comunidades de aves da Mata Atlântica. Dissertação (Mestrado em Ecologia), Universidade de São Paulo, São Paulo.

Manor, R., e D. Saltz. 2008. Conservation implications of competition between generalist and specialist rodents in Mediterranean afforested landscape. Biological Conservation 17:2513-2523.

McGill, B., R. Etienne, J. Gray, D. Alonso, M. Anderson, H. Benecha, M. Dornelas, B. Enquist, J. Green, F. He, A. Hurlbert, A. E. Magurran, P. Marquet, B. Maurer, A. Ostling, C. Soykan, K. Ugland e E. White. Species abundance distributions: moving beyond single prediction theories to integration within an ecological framework Ecology Letters 10:995-1015.

McIntyre, S. 1992. Risks associated with the setting of conservation priorities from rare plantspecies lists. Biological Conservation 60:31-37.

McIntyre, S., e R. Hobbs. 1999. Framework for conceptualizing human effects on landscapes and its relevance to management and research models Conservation Biology 13:12821292.

McKinney, M. L. 1997. Extinction vulnerability and selectivity: combining ecological and paleontological views. Annual Review of Ecology and Systematics 28:495-516.

Mendel, S. M., e M. V. Vieira. 2003. Movement distances and density estimation of small mammals using the spool-and-line technique. Acta Theriologica 48:289-300.

Mohr, C. O. 1947. Table of equivalent populations of North American small mammals. American Midland Naturalist 37:223-249.

Moilanen, A., e I. Hanski. 1998. Metapopulation dynamics: effects of habitat quality and landscape structure. Ecology 79:2503-2515.

Moore, R. P., W. D. Robinson, I. J. Lovette, e T. R. Robinson. 2008. Experimental evidence for extreme dispersal limitation in tropical forest birds. Ecology Letters 11:960-968.

Myers, N., R. A. Mittermeier, C. G. Mittermeier, G. A. B. Fonseca, e J. Kent. 2000. Biodiversity hotspots for conservation priorities. Nature 403:853-858.

Naxara, L. R. C. 2008. Importância dos corredores ripários para a fauna- pequenos mamíferos em manchas de floresta, matriz do entorno e elementos lineares em uma paisagem fragmentada de Mata Atlântica. Dissertação (Mestrado em Ecologia), Universidade de São Paulo, São Paulo.

Nee, S., e R. M. May. 1992. Dynamics of metapopulations - habitat festruction and competitive coexistence. Journal of Animal Ecology 61:37-40.

Öckinger, E., O. Schweiger, T. O. Crist, D. M. Debinski, J. Krauss, M. Kuussaari, J. D. Petersen, J. Pöyry, J. Settele, K. S. Summerville, e R. Bommarco. 2010. Life-history traits predict species responses to habitat area and isolation: a cross-continental synthesis. Ecology Letters 13:969-979.

Oliveira-Filho, A. T., e M. A. L. Fontes. 2000. Patterns of floristic differentiation among Atlantic Forests in Southeastern Brazil and the influence of climate. Biotropica 32:793-810.

Pardini, R. 2001. Pequenos mamíferos e a fragmentação da Mata Atlântica de Una, Sul da Bahia - processos e conservação. Tese (Doutorado em Zoologia), Universidade de São Paulo, São Paulo.

Pardini, R. 2004. Effects of forest fragmentation on small mammals in an Atlantic Forest landscape. Biodiversity and Conservation 13:2567-2586. 
Pardini, R., A. A. Bueno, T. A. Gardner, P. I. Prado, e J. P. Metzger. 2010. Beyond the fragmentation threshold hypothesis: regime shifts in biodiversity across fragmented landscapes. PLoS ONE 5:doi:10.1371/journal.pone.0013666.

Pardini, R., S. M. Souza, R. Braga- Neto, J. P. Metzger. 2005. The role of forest structure, fragment size and corridors in maintaining small mammal abundance and diversity in an Atlantic forest landscape. Biological Conservation 124: 253-266.

Pardini, R., e F. Umetsu. 2006. Pequenos mamíferos não-voadores da Reserva Florestal do Morro Grande - distribuição das espécies e da diversidade em uma área de Mata Atlântica. Biota $\quad$ Neotropica 6 (2). http://www.biotaneotropica.org.br/v6n2/pt/abstract?article+bn00606022006. ISSN 16760603.

Parmenter, R. R., T. L. Yates, D. R. Anderson, K. P. Burnham, J. L. Dunnum, A. B. Franklin, M. T. Friggens, B. C. Lubow, M. Miller, G. S. Olson, C. A. Parmenter, J. Pollard, E. Rexstad, T. M. Shenk, T. R. Stanley, e G. C. White. 2003. Small-mammal density estimation: a field comparison of grid-based vs. web-based density estimators. Ecological Monographs 73:1-26.

Passamani, M. 2000. Análise da comunidade de marsupiais em Mata Atlântica de Santa Teresa, Espírito Santo. Boletim Museu Biolologia Mello Leitão 11/12:215-228.

Pimm, S. L., H. L. Jones, e J. Diamond. 1988. On the risk of extinction. American Naturalist 132:757-785.

Pinotti, B., L. Naxara, e R. Pardini. 2011. Diet and food selection by small mammals in an oldgrowth Atlantic forest of south-eastern Brazil. Studies on Neotropical Fauna and Environment 46:1-9.

Pinotti, B.T. 2010. Pequenos mamíferos terrestres e a regeneração da Mata Atlântica: influência da estrutura do habitat e da disponibilidade de alimento na recuperação da fauna. Dissertação (Mestrado em Zoologia), Universidade de São Paulo, São Paulo.

Pires, A. S., P. Koeler Lira, F. A. S. Fernandez, G. M. Schittini, e L. C. Oliveira. 2002. Frequency of movements of small mammals among Atlantic coastal forest fragments in Brazil. Biological Conservation 108:229-237.

Pollock, K. H., J. D. Nichols, C. Brownie, e J. E. Hines. 1990. Statistical interference for capture-recapture experiments. Wildlife Monographs 107:92.

Prevedello, J. A., A. F. Mendoça, e M. V. Vieira. 2008. Uso de espaço por pequenos mamíferos: uma análise dos estudos realizados no Brasil. Oecologia Brasiliensis 12:610-625.

Prevedello, J. A. e, M. V. Vieira. 2010. Does the type of matrix matter? A quantitative review of the evidence. Biodiversity and Conservation 19:1205-1223.

Pulliam, H. R. 2000. On the relationship between niche and distribution. Ecology Letters 3:349361.

Purvis, A., J. L. Gittleman, G. Cowlishaw, e G. Mace. 2000a. Predicting extinction risk in declining species. Proceedings of the royal Society of London B 267:1947-1952.

Purvis, A., K. E. Jones, e G. M. Mace. 2000b. Extinction. Bioessays 22:1123-1133.

Püttker, T., C. S. Barros, T. K. Martins, S. Sommer, e R. Pardini. No prelo. The suitability of distance metrics as indices of home range size in tropical rodent species. Journal of Mammalogy.

Püttker, T., Y. Meyer-Lucht, e S. Sommer. 2008a. Fragmentation effects on population density of three rodent species in secondary Atlantic Rainforest, Brazil. Studies on Neotropical Fauna and Environment 43:11-18.

Püttker, T., R. Pardini, Y. Meyer-Lucht, e S. Sommer. 2008b. Responses of five small mammal species to micro-scale variations in vegetation structure in secondary Atlantic Forest remnants, Brazil. BMC Ecology 8:doi:10.1186/1472-6785-8-9. 
Quental, T. B., F. A. S. Fernandez, A. T. C. Dias, e F. S. Rocha. 2001. Population dynamics of the marsupial Micoureus demerarae in small fragments of Atlantic Coastal Forest in Brazil. Journal of Tropical Ecology 17:339-352.

R, Development Core Team 2010. R: A language and environment for statistical computing. R Foundation for Statistical Computing, Vienna, Austria.

Rabinowitz, D. 1981. Seven forms of rarity em The Biological aspects of rare plant conservation. H. Synge. Wiley.

Rabinowitz, D., J. K. Rapp, e P. M. Dixon. 1984. Competitive abilities of sparse grass species means of persistence or cause of abundance. Ecology 65:1144-1154.

Reynolds, J. D. 2003. Life histories and extinction risk. Páginas 195-217 em Macroecology: Concepts and Consequences (T. M. Blackburn, and K. J. Gaston, eds.). Blackwell Publishing, Oxford.

Ribeiro, M. C., J. P. Metzger, A. C. Martensen, F. J. Ponzoni, e M. M. Hirota. 2009. The Brazilian Atlantic Forest: How much is left, and how is the remaining forest distributed? Implications for conservation. Biological Conservation 142:1141-1153.

Rodríguez, A., G. Jansson, e H. Andrén. 2007. Composition of an avian guild in spatially structured habitats supports a competition-colonization trade-off. Proceedings of the Royal Society B-Biological Sciences 274:1403-1411.

Ross, J. L. S., e I. C. Moroz. 1997. Mapa Geomorfológico do Estado de São Paulo: escala 1:500.000. FFLCH-USP. IPT e Fapesp, São Paulo.

Rossi, N. F. 2011. Pequenos mamíferos não-voadores do Planalto Atlântico de São Paulo: identificação, história natural e ameaças. Dissertação (Mestrado em Zoologia), Universidade de São Paulo, São Paulo.

Szacki, J., e A. Liro, 1991. Movements of small mammals in the heterogeneous landscape. Landscape Ecology 5: 219-224

Schoener, T. W. 1981. An empirically based estimate of home range. Theoretical Population Biology 20: 281- 325.

Silva, J. A. A., A. D. Nobre, C. V. Manzatto, C. A. Joly, R. R. Rodrigues, L. A. Skorupa, C. A. Nobre, S. Ahrens, P. H. May, T. D. A. Sá, M. C. Cunha, e E. L. Rech Filho. 2011. Código Florestal e a Ciência: contribuições para o diálogo. Sociedade Brasileira para o Progresso da Ciência, Academia Brasileira de Ciências, São Paulo.

Slade, N. A., e L. A. Russell. 1998. Distances as indices to movements and home-range size from trapping records of small mammals. Journal of Mammalogy 79:346-351.

Slade, N. A., e R. K. Swihart. 1983. Home range indices for the hispid cotton rat (Sigmodon hispidus) in Northestern Kansas. Journal of Mammalogy 64:580-590.

Stickel, L. F. 1954. A comparison of certain methods of measuring ranges of small mammals. Journal of Mammalogy 35:1-15.

Swihart, R. K. e N. A. Slade, 1985. Testing For Independence of Observations in Animal Movements. Ecology 66: 1176-1184.

Swihart, R. K., T. M. Gehring, e M. B. Kolozsvary. 2003. Response of 'resistant' vertebrates to habitat loss and fragmentation: the importance of niche breadth and ange boundaries. Diversity and Distributions 9:1-18.

Thomas, C. D. 2000. Dispersal and extinction in fragmented landscapes. Proceedings of the Royal Society of London Series B-Biological Sciences 267:139-145.

Thornton, D., L. Branch, e M. Sunquist. 2011. Passive sampling effects and landscape location alter associations between species traits and response to fragmentation. Ecological Applications 21:817-829.

Tilman, D. 1994. Competition and biodiversity in spatially structured habitats. Ecology 75:2-16.

Tilman, D. 2004. Niche tradeoffs, neutrality, and community structure: a stochastic theory of resource competition, invasion, and community assembly. Proceedings of the National Academy of Sciences of the United States of America 101:10845-10861. 
Travis, J. M. J., e C. Dytham. 1999. Habitat persistence, habitat availability and the evolution of dispersal. Proceedings of the Royal Society of London Series B-Biological Sciences 266:723-728.

Umetsu, F. 2010. Diversidade de pequenos mamíferos em ambientes antropogênicos: espécies endêmicas e invasoras em paisagens de Mata Atlântica com diferentes porcentagens de perda da cobertura florestal. Tese (Doutorado em Zoologia), Universidade de São Paulo, São Paulo.

Umetsu, F., J. P. Metzger, e R. Pardini. 2008. Importance of estimating matrix quality for modeling species distribution in complex tropical landscapes: a test with Atlantic forest small mammals. Ecography 31:359-370.

Umetsu F., L. Naxara, e R. Pardini, 2006. Evaluating the efficiency of pitfall traps for sampling small mammals in the neotropics. Journal of Mammalogy 87:757-765.

Vetter, D., M. M. Hansbauer, Z. Vegvari, e I. Storch. 2011. Predictors of forest fragmentation sensitivity in Neotropical vertebrates: a quantitative review. Ecography 34:1-8.

Viveiros de Castro, E. B., e F. A. S. Fernandez. 2004. Determinants of differential extinction vulnerabilities of small mammals in Atlantic forest fragments in Brazil. Biological Conservation 119:73-80.

Voss, R. S., D. P. Lunde, e N. B. Simmons. 2001. The mammals of Paracou, French Guiana: A neotropical lowland rainforest fauna part 2. nonvolant. Bulletin of the American Museum of Natural History Number 263 :3-236. 2001.

Watling, J. I., e M. A. Donnelly. 2007. Multivariate correlates of extinction proneness in a naturally fragmented landscape. Diversity and Distributions 13:372-378.

White, G. C., D. R. Anderson, K. P. Burnham, e D. L. Otis. 1982. Capture-recapture and removal methods for sampling closed populations. Los Alamos National Laboratory, Los Alamos .

With, K. A., e A. W. King. 1999. Dispersal success on fractal landscapes: a consequence of lacunarity thresholds. Landscape Ecology 14: 73-82.

Williams, S. E., Y. M. Williams, J. VanDerWal, J. L. Isaac, L. P. Shoo, e C. N. Johnson. 2009. Ecological specialization and population size in a biodiversity hotspot: How rare species avoid extinction. Proceedings of the National Academy of Sciences of the United States of America 106:19737-19741.

Yu, J. P., e F. S. Dobson. 2000. Seven forms of rarity in mammals. Journal of Biogeography 27:131-139. 
Tabela 1: Hipóteses concorrentes disponíveis na literatura sobre os atributos ecológicos determinantes do risco de extinção.

\begin{tabular}{|c|c|}
\hline $\begin{array}{c}\text { Variável } \\
\text { independente }\end{array}$ & Hipóteses concorrentes \\
\hline- & $\begin{array}{l}\text { 1- O risco de extinção não é explicado pela } \\
\text { abundância local, capacidade de dispersão ou } \\
\text { amplitude de nicho das espécies. }\end{array}$ \\
\hline
\end{tabular}

2- Espécies com maior capacidade de dispersão têm maior requerimento de área e se deslocam Capacidade de dispersão

Capacidade de dispersão

Capacidade de dispersão com maior freqüência entre manchas de habitat, o que aumenta a mortalidade e, assim, o risco de extinção.

3- Espécies com maior capacidade de dispersão têm maior chance de recolonizar manchas de habitat ou ter suas populações resgatadas por indivíduos vindos de outras populações, diminuindo o risco de extinção.

4- Espécies com capacidade de dispersão intermediária têm maior risco de extinção, pois embora os indivíduos possuam maior requerimento de área e emigrem de manchas de habitat, não alcançam outras manchas. Assim, essas espécies apresentam alta mortalidade, alta emigração e baixa imigração.

5- Espécies com maior abundância têm menor risco de extinção, pois suas populações maiores Abundância local têm menor risco de extinção por eventos estocásticos de cunho ambiental, genético ou demográfico.

6- Há uma demanda conflitante entre a capacidade competitiva e a capacidade de colonização das espécies. As espécies melhores Abundância
local competidoras apresentam maior abundância, mas são piores colonizadoras, o que dificulta a recolonização de manchas de habitat ou o resgate de populações. Essas espécies têm, portanto, maior risco de extinção.

7- Espécies com menor amplitude de nicho têm maior risco de extinção local, pois possuem pouca

Amplitude plasticidade comportamental, fisiológica e de nicho

Fonte bibliográfica Gráfico

Travis \& Dytham 1999

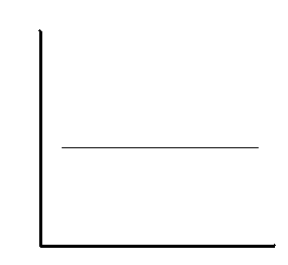

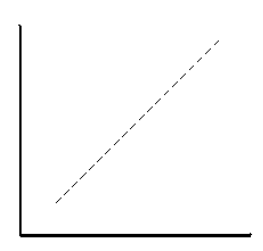
Hanski \& Ovaskainen 2003

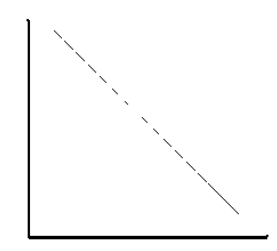

Thomas 2000

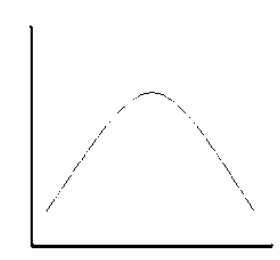

Pimm et al. 1988
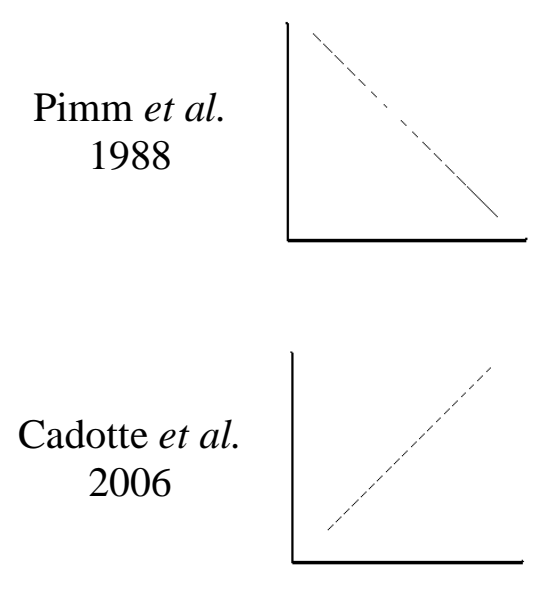
ecológica para adaptar-se a alterações ocorridas em seu ambiente.

Manor \& Saltz 2008 
Tabela 2: Número de indivíduos capturados das espécies de pequenos mamíferos em cada grade de armadilhas e no total na Reserva Florestal de Morro Grande.

\begin{tabular}{|c|c|c|c|c|}
\hline \multirow{2}{*}{ Espécie } & \multicolumn{4}{|c|}{ Número de indivíduos } \\
\hline & Grade 1 & Grade 2 & Grade 3 & Total \\
\hline \multicolumn{5}{|l|}{ Rodentia } \\
\hline \multicolumn{5}{|l|}{ Cricetidae } \\
\hline Oligoryzomys nigripes & 110 & 108 & 90 & 308 \\
\hline Akodon montensis & 159 & 77 & 45 & 281 \\
\hline Delomys sublineatus & 66 & 47 & 66 & 179 \\
\hline Thaptomys nigrita & 34 & 15 & 102 & 151 \\
\hline Euryoryzomys russatus & 41 & 49 & 43 & 133 \\
\hline Brucepattersonius soricinus & 32 & 29 & 9 & 70 \\
\hline Juliomys pictipes, J. ossitenuis & 1 & 4 & 11 & 16 \\
\hline Sooretamys angouya & 9 & 2 & 5 & 16 \\
\hline Bibimys labiosus & 2 & 1 & 0 & 3 \\
\hline Blarinomys breviceps & 0 & 1 & 1 & 2 \\
\hline Drymoreomys albimaculatus & 0 & 0 & 2 & 2 \\
\hline Nectomys squamipes & 1 & 0 & 0 & 1 \\
\hline Oxymycterus judex & 1 & 0 & 0 & 1 \\
\hline \multicolumn{5}{|l|}{ Echimyidae } \\
\hline Phyllomys nigrispinus, $P$. sulinus & 0 & 1 & 0 & 1 \\
\hline \multicolumn{5}{|l|}{ Didelphimorphia } \\
\hline \multicolumn{5}{|l|}{ Didelphidae } \\
\hline Marmosops incanus & 17 & 42 & 14 & 73 \\
\hline Monodelphis americana, $M$. scalops & 1 & 3 & 26 & 30 \\
\hline Monodelphis iheringi & 12 & 7 & 8 & 27 \\
\hline Gracilinanus microtarsus & 4 & 7 & 10 & 21 \\
\hline Monodelphis sp. n. & 0 & 1 & 15 & 16 \\
\hline Marmosops paulensis & 0 & 0 & 8 & 8 \\
\hline Marmosa paraguayana & 2 & 1 & 1 & 4 \\
\hline
\end{tabular}


Tabela 3: Índice do risco de extinção local das espécies de pequenos mamíferos registradas na Reserva Florestal do Morro Grande, calculado a partir do número de fragmentos (de um total de 50) e número de sítios em mata contínua (de um total de 18) em que foram capturadas em seis paisagens do Planalto Atlântico de São Paulo (dados de Pardini et al. 2010, Bueno 2008).

\begin{tabular}{|c|c|c|c|}
\hline Espécie & $\mathrm{N}^{0}$ de fragmentos & $\begin{array}{c}\mathrm{N}^{0} \text { de sítios em áreas } \\
\text { contínuas }\end{array}$ & $\begin{array}{l}\text { Risco de } \\
\text { extinção }\end{array}$ \\
\hline Akodon montensis & 47 & 13 & $-0,217$ \\
\hline Gracilinanus microtarsus & 37 & 10 & $-0,184$ \\
\hline Sooretamys angouya & 35 & 11 & $-0,088$ \\
\hline Marmosa paraguayana & 4 & 0 & $-0,080$ \\
\hline Oxymycterus judex & 9 & 2 & $-0,068$ \\
\hline Phyllomys spp. & 9 & 2 & $-0,068$ \\
\hline Bibimys labiosus & 3 & 0 & $-0,060$ \\
\hline Nectomys squamipes & 3 & 1 & $-0,004$ \\
\hline Oligoryzomys nigripes & 49 & 18 & 0,020 \\
\hline Blarinomys breviceps & 0 & 1 & 0,055 \\
\hline Brucepattersonius soricinus & 27 & 12 & 0,126 \\
\hline Marmosops incanus & 34 & 17 & 0,264 \\
\hline Monodelphis sp. n. & 3 & 6 & 0,273 \\
\hline Delomys sublineatus & 31 & 17 & 0,324 \\
\hline Marmosops paulensis & 0 & 6 & 0,333 \\
\hline Monodelphis spp. & 28 & 17 & 0,384 \\
\hline Drymoreomys albimaculatus & 0 & 7 & 0,388 \\
\hline Thaptomys nigrita & 12 & 15 & 0,593 \\
\hline Juliomys spp. & 17 & 17 & 0,604 \\
\hline Monodelphis iheringi & 0 & 11 & 0,611 \\
\hline Euryoryzomys russatus & 9 & 18 & 0,820 \\
\hline
\end{tabular}


Tabela 4: Medianas (entre sessões de amostragem) da abundância local das espécies de pequenos mamíferos em 6 ha da Reserva Florestal do Morro Grande, obtidas através do programa CAPTURE e do MNKA, e número de sessões de amostragem em que houve captura da espécie.

\begin{tabular}{|c|c|c|c|c|c|}
\hline \multirow[b]{2}{*}{ Espécie } & \multicolumn{2}{|c|}{ CAPTURE } & \multicolumn{2}{|c|}{ MNKA } & \multirow{2}{*}{$\begin{array}{c}\mathbf{N}^{\mathbf{0}} \text { de } \\
\text { sessões } \\
\text { com } \\
\text { captura }\end{array}$} \\
\hline & Mediana & $\begin{array}{c}\mathbf{N}^{0} \text { de } \\
\text { sessões }\end{array}$ & Mediana & $\begin{array}{c}\mathbf{N}^{\mathbf{0}} \text { de } \\
\text { sessões }\end{array}$ & \\
\hline Akodon montensis & 32,5 & 20 & 26 & 21 & 21 \\
\hline Delomys sublineatus & 17 & 16 & 15 & 21 & 21 \\
\hline Oligoryzomys nigripes & 11 & 5 & 15 & 21 & 21 \\
\hline Thaptomys nigrita & 16 & 10 & 14 & 21 & 21 \\
\hline Euryoryzomys russatus & 12,5 & 17 & 11 & 21 & 21 \\
\hline Marmosops incanus & 10 & 9 & 6 & 18 & 18 \\
\hline Brucepattersonius soricinus & 6 & 3 & 5 & 21 & 20 \\
\hline Monodelphis iheringi & 3 & 3 & 2 & 20 & 17 \\
\hline Monodelphis spp. & 2 & 3 & 1 & 16 & 16 \\
\hline Sooretamys angouya & - & 0 & 1 & 17 & 16 \\
\hline Bibimys labiosus & - & 0 & 0 & 3 & 3 \\
\hline Blarinomys breviceps & - & 0 & 0 & 2 & 2 \\
\hline Drymoreomys albimaculatus & - & 0 & 0 & 2 & 2 \\
\hline Juliomys spp. & - & 0 & 0 & 9 & 9 \\
\hline Nectomys squamipes & - & 0 & 0 & 1 & 1 \\
\hline Oxymycterus judex & - & 0 & 0 & 1 & 1 \\
\hline Phyllomys spp. & - & 0 & 0 & 1 & 1 \\
\hline Gracilinanus microtarsus & - & 0 & 0 & 9 & 9 \\
\hline Marmosa paraguayana & - & 0 & 0 & 6 & 6 \\
\hline Marmosops paulensis & - & 0 & 0 & 8 & 8 \\
\hline Monodelphis sp. $\mathrm{n}$. & - & 0 & 0 & 9 & 9 \\
\hline
\end{tabular}


Tabela 5: Área de vida estimada através do mínimo polígono convexo (MPC) e distância máxima percorrida para as espécies de pequenos mamíferos capturadas na Reserva Florestal do Morro Grande. Para as estimativas do tamanho da área de vida obtidas por MPC (mínimo polígono convexo), são apresentados o número de indivíduos com pelo menos quatro pontos de captura e os valores da mediana, máximo e mínimo entre os indivíduos da espécie. Para as distâncias máximas percorridas, são apresentados o número de indivíduos em que o cálculo da distância máxima percorrida foi possível, os valores da mediana, máximo e mínimo entre os indivíduos da espécie, a distribuição teórica com melhor ajuste aos dados e valor do quantil 0.90 da distribuição teórica.

\begin{tabular}{|c|c|c|c|c|c|c|c|c|c|c|}
\hline \multirow[b]{2}{*}{ Espécie } & \multicolumn{4}{|c|}{$\operatorname{MPC}\left(\mathrm{m}^{2}\right)$} & \multicolumn{6}{|c|}{ Distância máxima percorrida (m) } \\
\hline & $\begin{array}{c}\mathbf{N}^{\mathbf{0}} \\
\text { indivíduos }\end{array}$ & Mediana & Máximo & Mínimo & $\begin{array}{c}\mathbf{N}^{\mathbf{0}} \\
\text { indivíduos }\end{array}$ & Mediana & Máximo & Mínimo & Distribuição & $\begin{array}{c}\text { Quantil } \\
\mathbf{0 . 9 0}\end{array}$ \\
\hline Akodon montensis & 34 & 750 & 6900 & 100 & 109 & 30,00 & 189,74 & 0 & gamma & 108,54 \\
\hline Delomys sublineatus & 20 & 1050 & 3200 & 300 & 66 & 41,23 & 145,60 & 0 & gamma & 104,4 \\
\hline Euryoryzomys russatus & 10 & 1100 & 2400 & 200 & 53 & 50 & 160,31 & 0 & gamma & 122,18 \\
\hline Marmosops incanus & 6 & 1600 & 1400 & 1000 & 25 & 50 & 121,66 & 20 & lognormal & 94,72 \\
\hline Thaptomys nigrita & 3 & 200 & 2800 & 100 & 28 & 35 & 107,70 & 0 & gamma & 91,03 \\
\hline Oligoryzomys nigripes & 3 & 1200 & 1200 & 200 & 21 & 60 & 85,44 & 10 & normal & 78,98 \\
\hline Brucepattersonius soricinus & 1 & 400 & - & - & 15 & 41,23 & 120 & 10 & gamma & 82,06 \\
\hline Bibimys labiosus & 0 & - & - & - & 1 & 10 & - & - & - & - \\
\hline Sooretamys angouya & 0 & - & - & - & 3 & 57,32 & 60,83 & 50 & - & - \\
\hline Marmosa paraguayana & 0 & - & - & - & 2 & 73,38 & 104,40 & 42,36 & - & - \\
\hline Marmosops paulensis & 0 & - & - & - & 3 & 101,98 & 113,14 & 20 & - & - \\
\hline Monodelphis spp. & 0 & - & - & - & 2 & 35,41 & 36,06 & 34,76 & - & - \\
\hline Monodelphis iheringi & 0 & - & - & - & 4 & 31,80 & 56,57 & 44,28 & - & - \\
\hline Monodelphis sp.n. & 0 & - & - & - & 1 & 40 & - & - & - & - \\
\hline
\end{tabular}


Tabela 6: Classificação da amplitude de nicho das espécies de pequenos mamíferos capturadas na Reserva Florestal do Morro Grande, a partir dos dados de Umetsu (2010) e Bueno (2008), compilados por Rossi (2011).

\begin{tabular}{|c|c|}
\hline Espécie & Amplitude de nicho \\
\hline Brucepattersonius soricinus & Alta especialização no habitat florestas nativas \\
\hline Delomys sublineatus & Alta especialização no habitat florestas nativas \\
\hline Euryoryzomys russatus & Alta especialização no habitat florestas nativas \\
\hline Thaptomys nigrita & Alta especialização no habitat florestas nativas \\
\hline Drymoreomys albimaculatus & Alta especialização no habitat florestas nativas \\
\hline Phyllomys spp. & Alta especialização no habitat florestas nativas \\
\hline Marmosops incanus & Alta especialização no habitat florestas nativas \\
\hline Marmosops paulensis & Alta especialização no habitat florestas nativas \\
\hline Monodelphis spp. & Alta especialização no habitat florestas nativas \\
\hline Monodelphis iheringi & Alta especialização no habitat florestas nativas \\
\hline Monodelphis sp. n. & Alta especialização no habitat florestas nativas \\
\hline Sooretamys angouya & Média especialização no habitat florestas nativas \\
\hline Juliomys spp. & Média especialização no habitat florestas nativas \\
\hline Gracilinanus microtarsus & Média especialização no habitat florestas nativas \\
\hline Akodon montensis & Baixa especialização no habitat florestas nativas \\
\hline Oligoryzomys nigripes & Baixa especialização no habitat florestas nativas \\
\hline Oxymycterus judex & Baixa especialização no habitat florestas nativas \\
\hline Bibimys labiosus & Não especializada no habitat florestas nativas \\
\hline Marmosa paraguayana & $\begin{array}{l}\text { Espécie não ocorreu na área continua amostrada por Bueno } \\
\qquad(2008)\end{array}$ \\
\hline Blarinomys breviceps & $\begin{array}{c}\text { Não foi possível classificar devido ao pequeno número de } \\
\text { indivíduos capturados }\end{array}$ \\
\hline Nectomys squamipes & $\begin{array}{c}\text { Não foi possível classificar devido ao pequeno número de } \\
\text { indivíduos capturados }\end{array}$ \\
\hline
\end{tabular}


Tabela 7: Resultado da seleção de modelos do risco de extinção em função da capacidade de dispersão, abundância local e amplitude de nicho para sete espécies de pequenos mamíferos capturadas na Reserva Florestal do Morro Grande. k = número de parâmetros; log.lik = máxima verossimilhança; $\Delta . \mathrm{AICc}=$ diferença entre o AICc do modelo considerado e do melhor modelo; wi.AICc $=$ peso de evidência. Modelos selecionados estão sombreados.

\begin{tabular}{clcccccc}
\hline Modelo & \multicolumn{1}{c}{ Variáveis } & Coeficiente & $\mathbf{k}$ & log.lik & AICc & $\Delta . A I C c$ & wi.AICc \\
\hline A & Nulo & - & 2 & $-2,024$ & 11,048 & 0 & 0,6464 \\
E & Amplitude de nicho & $-0,524$ & 3 & 0,679 & 12,641 & 1,593 & 0,2915 \\
D & Abundância local & $-0,021$ & 3 & $-1,304$ & 16,608 & 5,560 & 0,0401 \\
B & Capacidade de dispersão & 0,003 & 3 & $-1,919$ & 17,838 & 6,789 & 0,0206 \\
C & Capacidade de dispersão & 0,001 & 3 & $-6,584$ & 27,169 & 16,120 & 0,0002 \\
\hline
\end{tabular}


Tabela 8: Resultado da seleção de modelos do risco de extinção em função da abundância local e amplitude de nicho para 18 espécies de pequenos mamíferos capturadas na Reserva Florestal do Morro Grande. $\mathrm{k}$ = número de parâmetros; log.lik = máxima verossimilhança; $\Delta$.AICc $=$ diferença entre o AICc do modelo considerado e do melhor modelo; wi.AICc= peso de evidência. Modelos selecionados estão sombreados.

\begin{tabular}{clcccccc}
\hline Modelo & \multicolumn{1}{c}{ Variáveis } & Coeficiente & $\mathbf{k}$ & log.lik & AICc & $\Delta . A I C c$ & wi.AICc \\
\hline E & Amplitude de nicho & $-0,193$ & 3 & 0,178 & 7,358 & 0 & 0,715 \\
F & Abundância local & 0,003 & 4 & 0,238 & 10,599 & 3,241 & 0,1414 \\
& Amplitude de nicho & $-0,196$ & & & & & \\
& Abundância local & 0,031 & 5 & 1,635 & 11,728 & 4,37 & 0,0803 \\
G & Amplitude de nicho & $-0,128$ & & & & & \\
& Interação & $-0,013$ & & & & & \\
A & Nulo & - & 2 & $-3,916$ & 12,632 & 5,274 & 0,0511 \\
D & Abundância local & $-0,001$ & 3 & $-3,909$ & 15,534 & 8,175 & 0,0119 \\
\hline
\end{tabular}


Figura 1: Mapa das três regiões e seis paisagens indicando as áreas de mata (cinza) e os sítios em que foram amostradas as assembléias de pequenos mamíferos no Planalto Atlântico Paulista, SP. 1 - municípios de Cotia e Ibiúna, 2 - municípios de Ribeirão grande e Capão Bonito, 3 municípios de Tapiraí e Piedade.

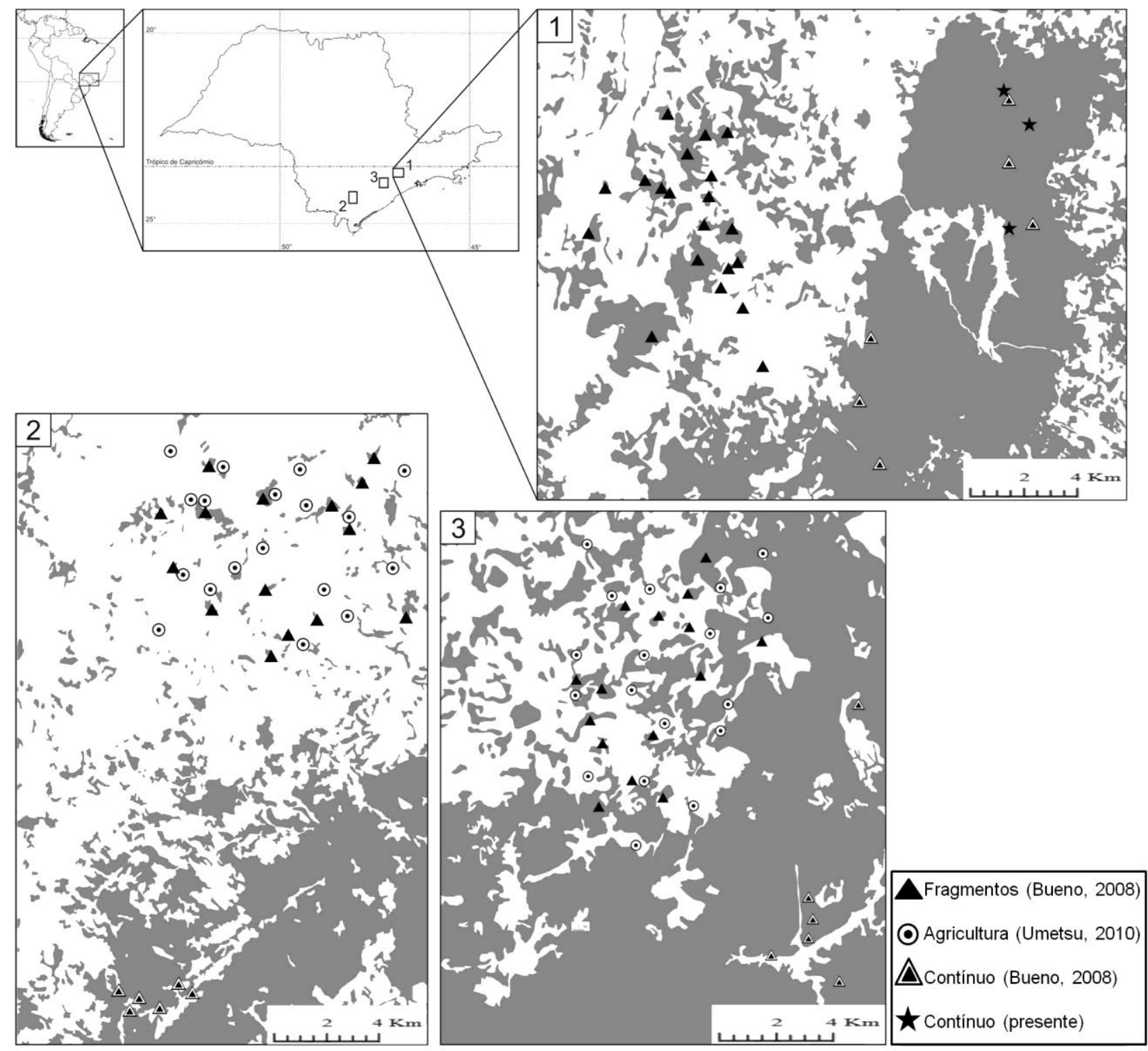




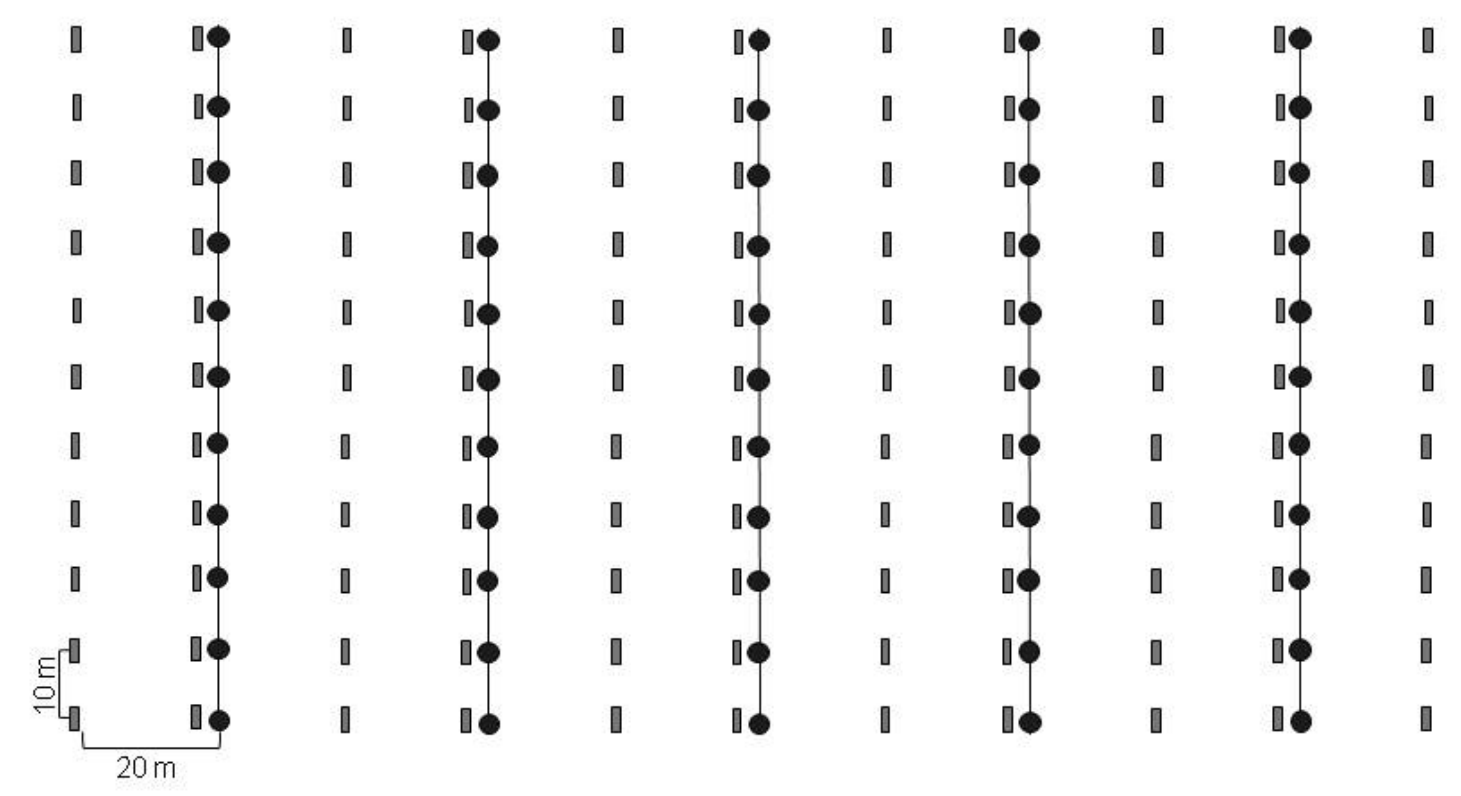

Figura 2: Esquema da grade de armadilhas (2 ha) utilizada para captura de pequenos mamíferos na Reserva Florestal de Morro Grande. Retângulos representam armadilhas tipo sherman e círculos representam armadilhas de interceptação e queda, conectadas por cercas-guia (linhas). 


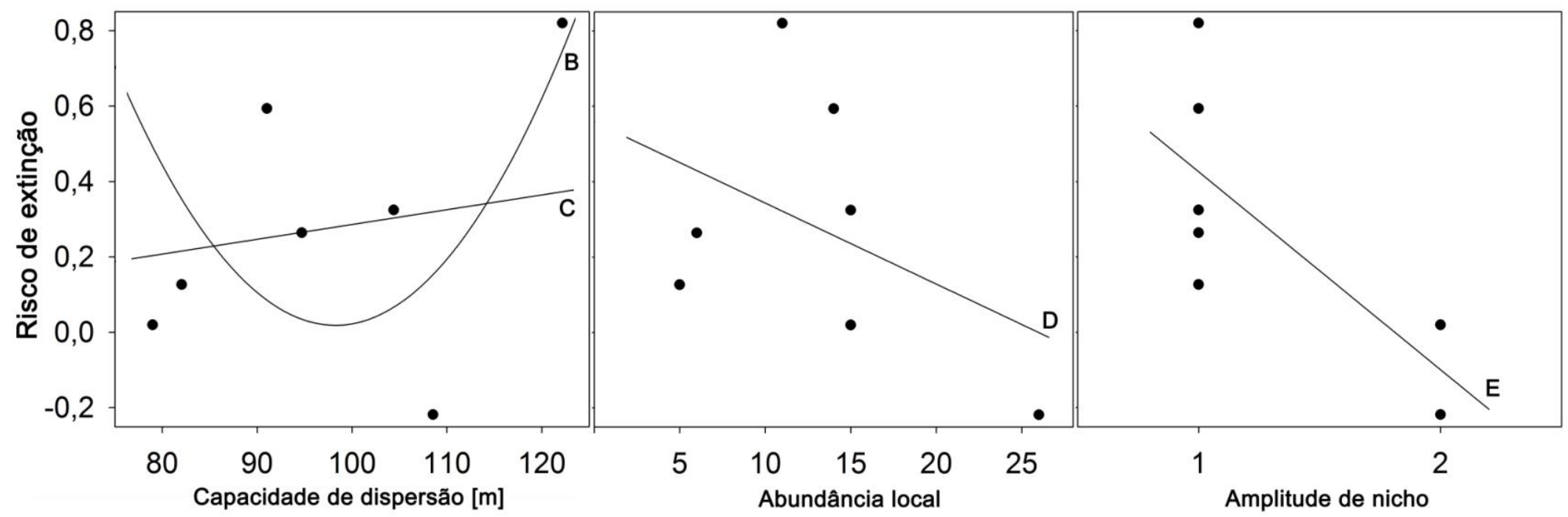

Figura 3: Relações entre os valores observados de risco de extinção e capacidade de dispersão, abundância local e amplitude de nicho para sete espécies de pequenos mamíferos da Reserva Florestal do Morro Grande. As retas e curvas representam as funções matemáticas dos modelos de B a E da primeira seleção de modelos (Tabela 7). 


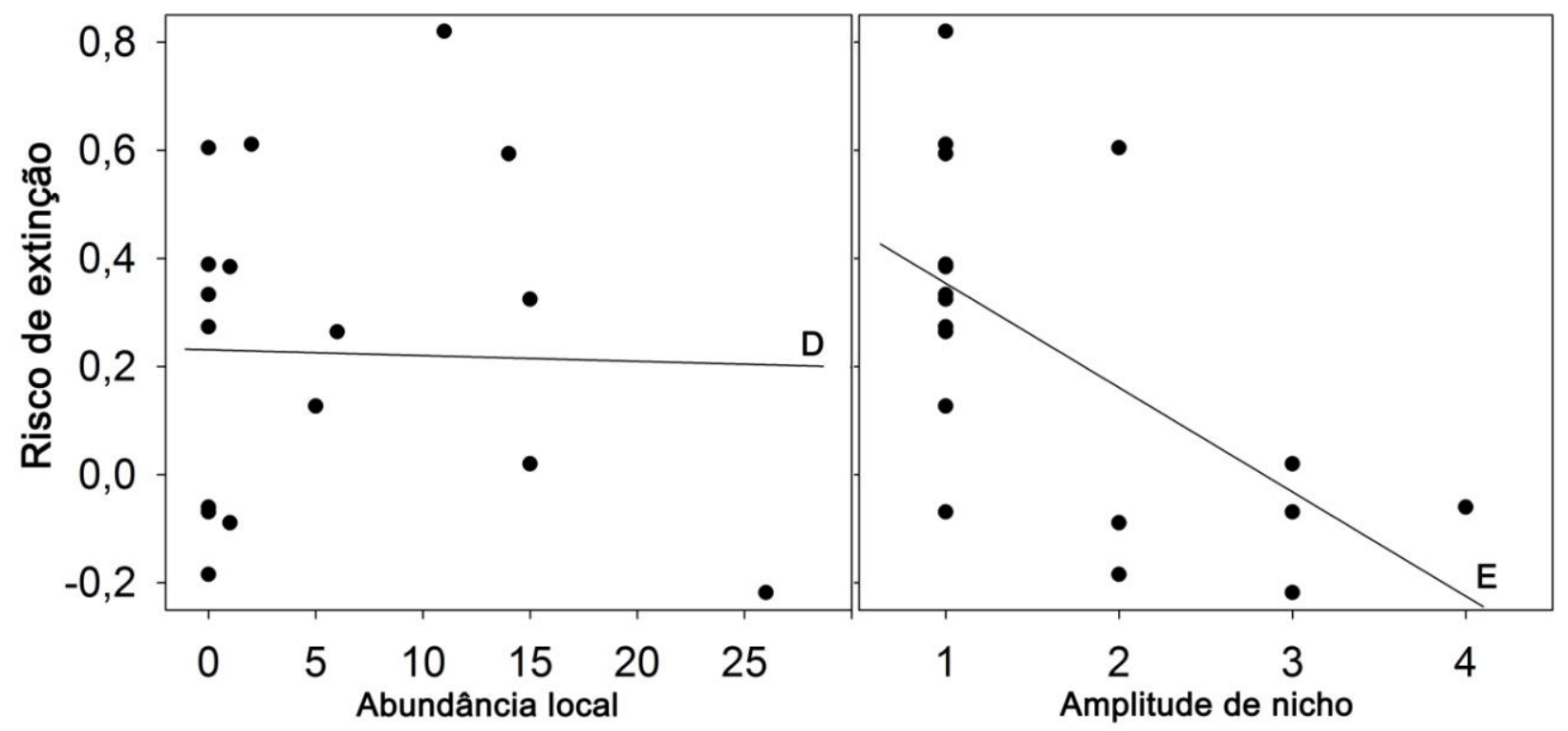

Figura 4: Relações entre os valores observados de risco de extinção e abundância local e amplitude de nicho para 18 espécies de pequenos mamíferos da Reserva Florestal do Morro Grande. As retas representam as funções matemáticas dos modelos D e E da segunda seleção de modelos (Tabela 8). 
ANEXO 1: Sessão de captura, número de indivíduos capturados, e abundância obtida por dois métodos diferentes para as espécies de pequenos mamíferos capturadas na Reserva Florestal do Morro Grande. Para as estimativas obtidas com o CAPTURE, são apresentados também o modelo selecionado, a probabilidade de captura estimada e os erros padrão associados às estimativas de abundância. M0 = probabilidade de captura constante; $\mathrm{Mt}$ = probabilidades de captura variando em função do tempo (dias); $\mathrm{Mh}$ = probabilidades de captura variando entre indivíduos; $\mathrm{Mb}=$ probabilidades de captura variando em função da primeira captura do indivíduo; Mtb, Mth, Mbh, Mtbh = combinam as fontes de variação nas probabilidades. Apenas sessões com estimativas de probabilidade de captura maiores que 0,2 foram consideradas. Nas sessões em que houve mais de um modelo selecionado pelo CAPTURE, o modelo mais simples foi o utilizado. Caso o modelo utilizado tivesse mais de uma estimativa de probabilidade de captura (Mt, Mth, Mh), ou estimativa de probabilidade de recaptura (Mb, Mbh), foi considerada a média entre os valores de probabilidade de captura e/ou de recaptura. Em três sessões o modelo Mtbh foi selecionado pelo CAPTURE. Como não há estimativa para este modelo, o modelo M0 foi o utilizado. * = sessão em que dois modelos foram selecionados. ** = sessão em que o modelo Mtbh foi selecionado pelo CAPTURE.

\begin{tabular}{|c|c|c|c|c|c|c|c|}
\hline \multirow[b]{2}{*}{ Espécie } & \multirow[b]{2}{*}{$\begin{array}{l}\text { Sessão de } \\
\text { captura }\end{array}$} & \multirow[b]{2}{*}{$\begin{array}{c}\mathrm{N}^{0} \text { de } \\
\text { indivíduos }\end{array}$} & \multicolumn{4}{|c|}{ CAPTURE } & \multirow{2}{*}{$\begin{array}{c}\text { MNKA } \\
\text { Abundância }\end{array}$} \\
\hline & & & $\begin{array}{c}\text { Modelo } \\
\text { selecionado }\end{array}$ & $\begin{array}{l}\text { Probabilidade } \\
\text { de captura }\end{array}$ & Abundância & Erro padrão & \\
\hline A. montensis & março/2008 & 30 & M0 & 0,33 & 34 & 2,84 & 30 \\
\hline A. montensis & abril(01)/2008 & 63 & Mth & 0,33 & 77 & 7,45 & 64 \\
\hline A. montensis & $\operatorname{abril}(02) / 2008$ & 38 & $\mathrm{Mh}$ & 0,24 & 65 & 17,62 & 46 \\
\hline A. montensis & maio/2008 & 41 & $\mathrm{Mh}$ & 0,37 & 52 & 6,20 & 45 \\
\hline A. montensis & junho/2008 & 41 & $\mathrm{Mh}^{*}$ & 0,30 & 45 & 1,13 & 43 \\
\hline A. montensis & julho/2008 & 31 & $\mathrm{Mbh}$ & 0,77 & 31 & 0,28 & 32 \\
\hline A. montensis & agosto/2008 & 40 & Mth & 0,37 & 55 & 7,60 & 40 \\
\hline A. montensis & setembro/2008 & 21 & Mth & 0,51 & 26 & 3,69 & 21 \\
\hline A. montensis & outubro/2008 & 29 & Mth & 0,35 & 41 & 7,40 & 30 \\
\hline A. montensis & novembro/2008 & 18 & Mth & 0,28 & 23 & 4,96 & 19 \\
\hline A. montensis & dezembro/2008 & 42 & $\mathrm{Mb}$ & 0,22 & 49 & 4,03 & 42 \\
\hline A. montensis & janeiro/2009 & 26 & M0* & 0,45 & 27 & 1,30 & 26 \\
\hline A. montensis & fevereiro/2009 & 32 & M0 & 0,42 & 34 & 1,77 & 32 \\
\hline A. montensis & março/2009 & 19 & M0 & 0,33 & 21 & 2,20 & 19 \\
\hline
\end{tabular}



A. montensis
A. montensis
A. montensis
A. montensis
A. montensis
A. montensis
B. soricinus
B. soricinus
B. soricinus
B. soricinus
D. sublineatus
D. sublineatus
D. sublineatus
D. sublineatus
D. sublineatus
D. sublineatus
D. sublineatus
D. sublineatus
D. sublineatus
D. sublineatus
D. sublineatus
D. sublineatus
D. sublineatus
D. sublineatus
D. sublineatus
D. sublineatus
E. russatus
E. russatus
E. russatus
E. russatus
E. russatus

abril/2009

15

maio/2009

M0

junho/2009

M0*

0,41

1,28

julho/2009

Mth

0,31

agosto/2009

M0*

0,47

outubro/2009 9

junho/2009 8

julho/2008 4

agosto/2008 $\quad 10$

junho/2009 3

abril(01)/2008 $\quad 15$

abril(02)/2008 27

maio/2008 18

junho/2008 13

julho/2008 31

agosto/2008 25

setembro/2008 27

outubro/2008 16

novembro/2008 16

dezembro/2008 4

fevereiro/2009 6

março/2009 16

julho/2009 26

agosto/2009 10

setembro/2009 10

março/2008 10

março/2008 20

abril(01)/2008 22

abril $(02) / 2008 \quad 14$

maio/2008 11

junho/2008

10

M0

0,46

0,38

0,47

0,20

0,44

0,21

0,33

0,31

0,45

0,35

0,31

0,37

0,43

0,57

0,31

0,26

0,35

0,37

0,27

0,20

$\begin{array}{ll}\text { Mth } & 0,22 \\ \text { M0* } & 0,25\end{array}$

$\begin{array}{cc}\text { M0* } & 0,25 \\ \text { M0 } & 0,38\end{array}$

M0* $\quad 0,46$

M0 $\quad 0,39$

M0 $\quad 0,45$

M0 $\quad 0,50$ 


\begin{tabular}{|c|c|c|c|c|c|c|c|}
\hline E. russatus & julho/2008 & 10 & M0* & 0,58 & 10 & 0,38 & 11 \\
\hline E. russatus & agosto/2008 & 10 & M0* & 0,41 & 10 & 1,03 & 10 \\
\hline E. russatus & setembro/2008 & 9 & Mth & 0,40 & 9 & 1,15 & 9 \\
\hline E. russatus & outubro/2008 & 10 & $\mathrm{M} 0 * *$ & 0,35 & 11 & 1,44 & 10 \\
\hline E. russatus & janeiro/2009 & 19 & M0 & 0,30 & 22 & 2,68 & 20 \\
\hline E. russatus & fevereiro/2009 & 14 & M0 & 0,54 & 14 & 0,57 & 15 \\
\hline E. russatus & março/2009 & 9 & M0 & 0,38 & 9 & 1,12 & 10 \\
\hline E. russatus & junho/2009 & 14 & M0 & 0,21 & 19 & 4,35 & 16 \\
\hline E. russatus & julho/2009 & 7 & $\mathrm{Mh}$ & 0,15 & 13 & 4,11 & 8 \\
\hline E. russatus & agosto/2009 & 9 & $\mathrm{Mh}$ & 0,31 & 12 & 5,29 & 9 \\
\hline E. russatus & setembro/2009 & 12 & M0* & 0.32 & 13 & 1,85 & 12 \\
\hline E. russatus & outubro/2009 & 7 & Mth & 0,27 & 11 & 4,31 & 7 \\
\hline Monodelphis spp. & maio/2008 & 2 & M0 & 0,30 & 2 & 0,84 & 2 \\
\hline Monodelphis spp. & novembro/2008 & 3 & M0 & 0,21 & 4 & 1,98 & 3 \\
\hline Monodelphis spp. & fevereiro/2009 & 2 & M0 & 0,30 & 2 & 0,84 & 2 \\
\hline M. iheringi & março/2008 & 3 & $\mathrm{Mbh}^{*}$ & 0,84 & 3 & 0,06 & 3 \\
\hline M. iheringi & novembro/2008 & 3 & M0 & 0,33 & 3 & 0,86 & 3 \\
\hline M. iheringi & fevereiro/2009 & 3 & M0 & 0,21 & 4 & 1,98 & 4 \\
\hline M. incanus & $\operatorname{março/2008}$ & 6 & M0 & 0,50 & 6 & 0,48 & 6 \\
\hline M. incanus & abril(01)/2008 & 14 & M0* & 0,26 & 17 & 3,02 & 14 \\
\hline M. incanus & maio/2008 & 12 & Mbh* & 0,37 & 13 & 2,35 & 12 \\
\hline M. incanus & junho/2008 & 11 & M0 & 0,64 & 10 & 0,25 & 13 \\
\hline M. incanus & agosto/2008 & 9 & M0 & 0,22 & 11 & 0,44 & 10 \\
\hline M. incanus & setembro/2008 & 4 & M0 & 0,26 & 5 & 1,60 & 4 \\
\hline M. incanus & janeiro/2009 & 11 & $\mathrm{Mb}$ & 0,35 & 11 & 0,45 & 11 \\
\hline M. incanus & abril/2009 & 2 & M0 & 0,30 & 2 & 0,84 & 5 \\
\hline M. incanus & maio/2009 & 5 & M0 & 0,20 & 7 & 2,76 & 6 \\
\hline O. nigripes & março/2008 & 27 & M0 & 0,24 & 35 & 5,02 & 27 \\
\hline O. nigripes & maio/2008 & 9 & M0* & 0,28 & 11 & 2,13 & 11 \\
\hline O. nigripes & julho/2008 & 10 & $\mathrm{M} 0 *$ & 0,32 & 11 & 1,74 & 11 \\
\hline$O$. nigripes & agosto/2008 & 38 & M0** & 0,56 & 38 & 0,38 & 38 \\
\hline
\end{tabular}




\begin{tabular}{|c|c|c|c|c|c|c|c|}
\hline O. nigripes & setembro/2008 & 3 & M0 & 0,40 & 3 & 0,59 & 4 \\
\hline T. nigrita & junho/2008 & 21 & Mt & 0,31 & 24 & 2,59 & 21 \\
\hline T. nigrita & agosto/2008 & 20 & Mbh & 0,50 & 20 & 1,13 & 21 \\
\hline T. nigrita & outubro/2008 & 17 & M0 & 0,37 & 18 & 1,72 & 18 \\
\hline T. nigrita & novembro/2008 & 12 & $\mathrm{M} 0 * *$ & 0,53 & 12 & 0,93 & 15 \\
\hline T. nigrita & fevereiro/2009 & 6 & M0 & 0,35 & 6 & 1,09 & 6 \\
\hline T. nigrita & outubro/2009 & 11 & M0 & 0,25 & 12 & 2,68 & 10 \\
\hline
\end{tabular}


ANEXO 2: Correlação entre 87 estimativas de abundância do CAPTURE e valores de MNKA (r $=0,9079 ; p<0,001)$ para nove espécies de pequenos mamíferos da Reserva Florestal do Morro Grande.

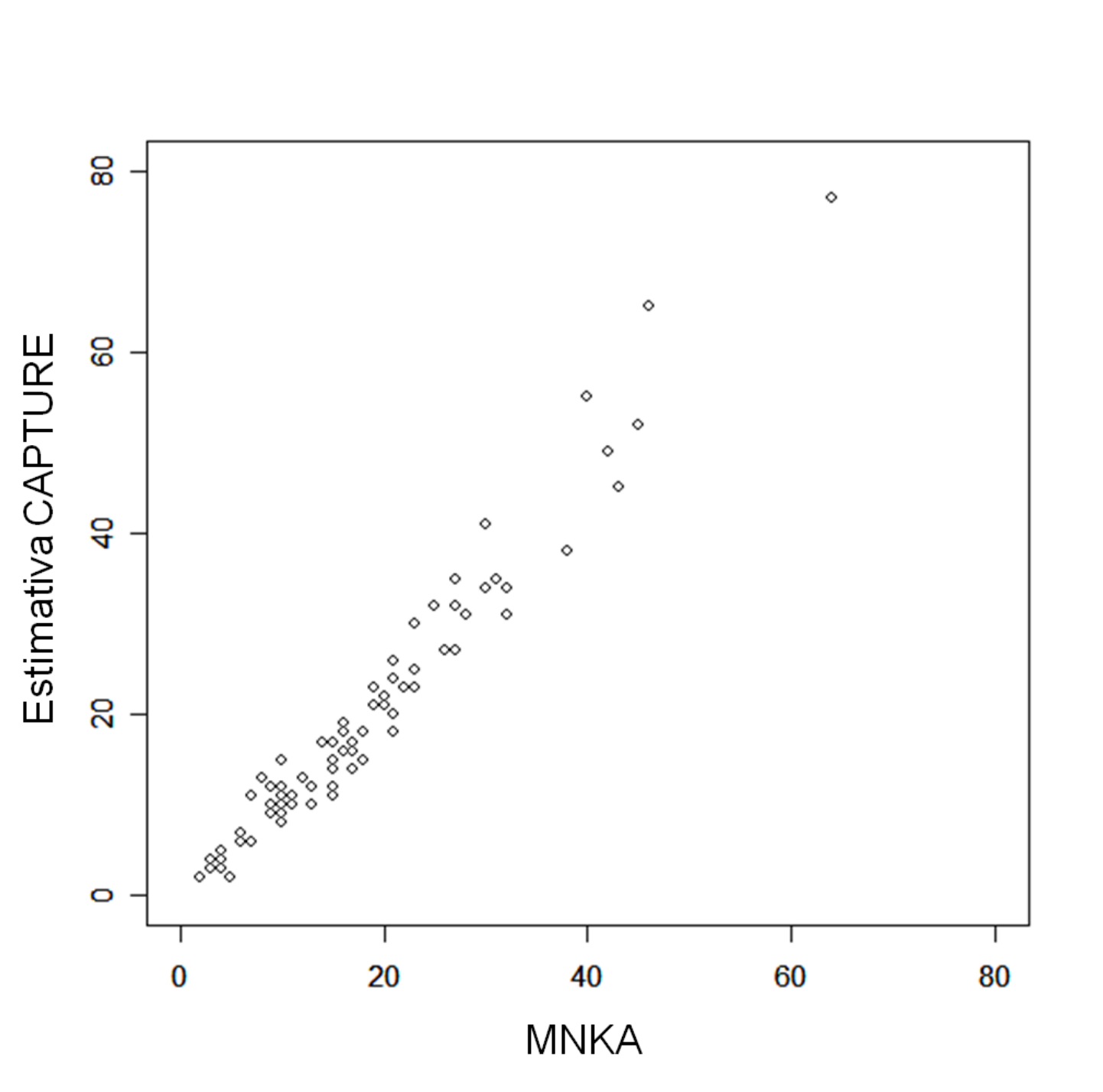


ANEXO 3: Número de indivíduos, mediana e valores máximos (Máx) e mínimos (Mín) das estimativas do tamanho da área de vida das espécies de pequenos mamíferos capturadas na Reserva Florestal do Morro Grande, considerando-se um mínimo de três (MPC3), quatro (MPC4) e cinco (MPC5) pontos de captura por indivíduo.

\begin{tabular}{|c|c|c|c|c|c|c|c|c|c|c|c|c|}
\hline \multirow{2}{*}{ Espécie } & \multicolumn{4}{|c|}{ Área de vida - MPC3 $\left(\mathrm{m}^{2}\right)$} & \multicolumn{4}{|c|}{ Área de vida - MPC4 $\left(\mathbf{m}^{2}\right)$} & \multicolumn{4}{|c|}{ Área de vida - MPC5 $\left(\mathrm{m}^{2}\right)$} \\
\hline & Indivíduos & Mediana & Máx & Mín & Indivíduos & Mediana & Máx & Mín & Indivíduos & Mediana & Máx & Mín \\
\hline Akodon montensis & 52 & 550 & 6900 & 100 & 34 & 750 & 6900 & 100 & 23 & 900 & 5400 & 100 \\
\hline Delomys sublineatus & 28 & 600 & 3200 & 100 & 20 & 1050 & 3200 & 300 & 12 & 1200 & 2500 & 300 \\
\hline Euryoryzomys russatus & 22 & 750 & 3200 & 100 & 10 & 1100 & 2400 & 200 & 7 & 1400 & 2400 & 400 \\
\hline Oligoryzomys nigripes & 10 & 850 & 1400 & 100 & 3 & 1200 & 1400 & 1000 & 1 & 1000 & - & - \\
\hline Marmosops incanus & 8 & 1600 & 3400 & 100 & 6 & 1600 & 2800 & 100 & 3 & 2700 & 2800 & 1100 \\
\hline Thaptomys nigrita & 4 & 300 & 1200 & 200 & 3 & 200 & 1200 & 200 & 3 & 200 & 1200 & 200 \\
\hline Brucepattersonius soricinus & 3 & 200 & 400 & 200 & 1 & 400 & - & - & 1 & 400 & - & - \\
\hline Sooretamys angouya & 1 & 2200 & - & - & 0 & - & - & - & 0 & - & - & - \\
\hline Marmosops paulensis & 1 & 4800 & - & - & 0 & - & - & - & 0 & - & - & - \\
\hline Monodelphis spp. & 1 & 300 & - & - & 0 & - & - & - & 0 & - & - & - \\
\hline Bibimys labiosus & 0 & - & - & - & 0 & - & - & - & 0 & - & - & - \\
\hline Blarinomys breviceps & 0 & - & - & - & 0 & - & - & - & 0 & - & - & - \\
\hline Drymoreomys albimaculatus & 0 & - & - & - & 0 & - & - & - & 0 & - & - & - \\
\hline Juliomys spp. & 0 & - & - & - & 0 & - & - & - & 0 & - & - & - \\
\hline Nectomys squamipes & 0 & - & - & - & 0 & - & - & - & 0 & - & - & - \\
\hline Oxymycterus judex & 0 & - & - & - & 0 & - & - & - & 0 & - & - & - \\
\hline Phyllomys spp. & 0 & - & - & - & 0 & - & - & - & 0 & - & - & - \\
\hline Gracilinanus microtarsus & 0 & - & - & - & 0 & - & - & - & 0 & - & - & - \\
\hline Marmosa paraguayanus & 0 & - & - & - & 0 & - & - & - & 0 & - & - & - \\
\hline Monodelphis iheringi & 0 & - & - & - & 0 & - & - & - & 0 & - & - & - \\
\hline Monodelphis sp. n. & 0 & - & - & - & 0 & - & - & - & 0 & - & - & - \\
\hline
\end{tabular}


ANEXO 4: Correlação entre o número de valores obtidos de distância percorrida entre sessões de amostragem sucessivas e o valor da distância máxima percorrida $(r=0,2243 ; \mathrm{p}=0,0190)$ para os indivíduos da espécie Akodon montensis nas três grades de armadilhas da Reserva Florestal do Morro Grande.

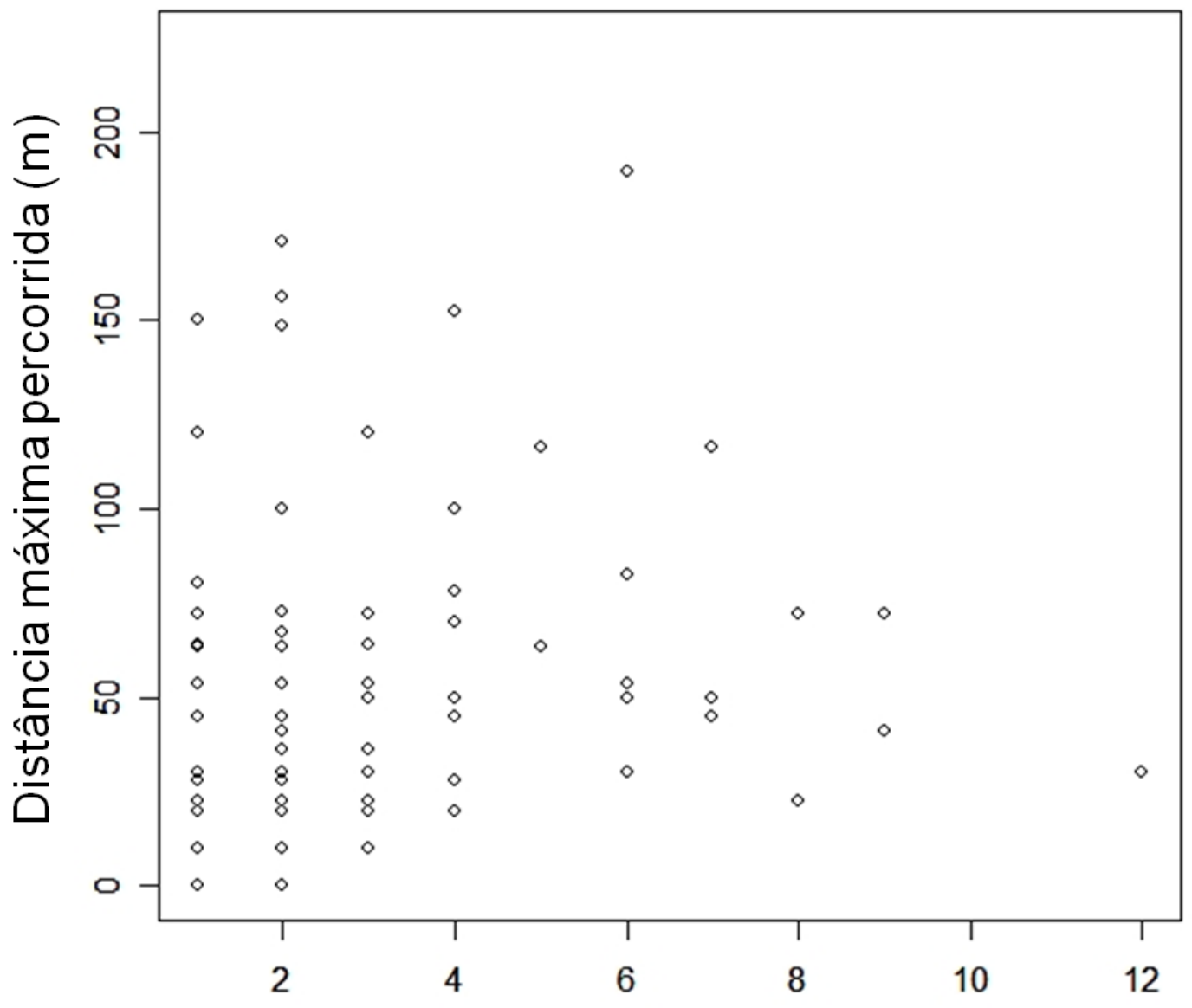

Número de capturas por indivíduo 
ANEXO 5: Correlação entre a estimativa do tamanho da área de vida (MPC), com pelo menos quatro pontos de captura, e máxima distância percorrida entre sessões de captura sucessivas ( $\mathrm{r}=$ 0,6876; $\mathrm{p}<0,001)$ para 77 indivíduos de sete espécies de pequenos mamíferos capturados na Reserva Florestal do Morro Grande.

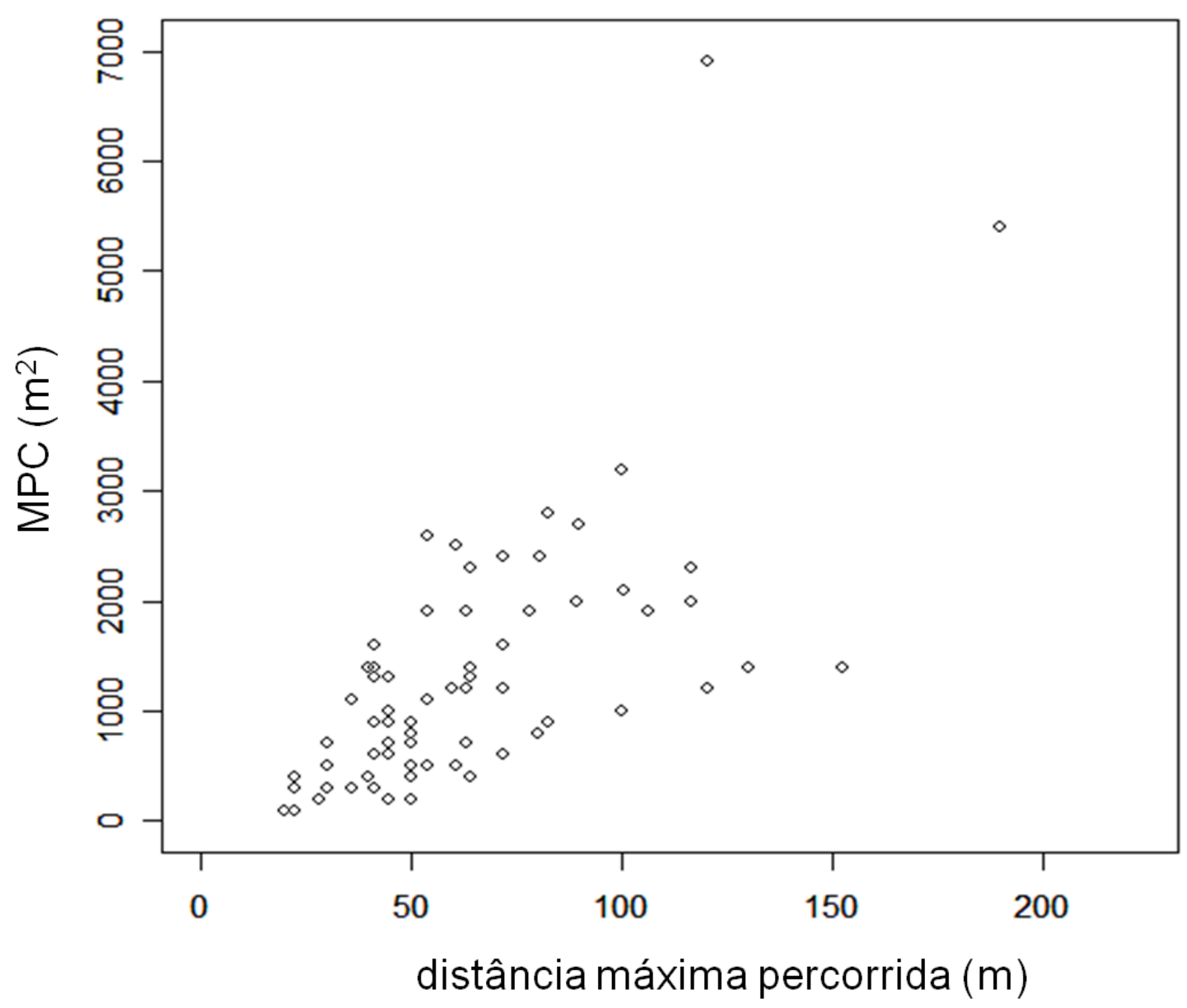


ANEXO 6: Seleção de modelos para a distribuição dos dados de distância máxima percorrida pelos indivíduos das espécies de pequenos mamíferos capturadas na Reserva Florestal do Morro Grande. O conjunto de modelo candidatos se refere a diferentes distribuições de probabilidades teóricas gamma, lognormal, weibull, exponencial e normal, truncadas no valor 223,60 m (máxima distância entre armadilhas, na grade de armadilhas). $\mathrm{k}$ = número de parâmetros; log.lik= máxima verossimilhança; $\triangle \mathrm{AICc}=$ diferença entre o AICc do modelo considerado e do melhor modelo; wi.AICc = peso de evidência. Modelos selecionados estão sombreados.

\section{Espécie}

Akodon montensis

\begin{tabular}{lccccc}
\hline distribuição teórica & $\mathbf{k}$ & log.lik & AICc & $\Delta . A I C c$ & wi.AICc \\
\hline gamma & 2 & $-478,119$ & 960,351 & 0 & 0,9698 \\
lognormal & 2 & $-481,666$ & 967,444 & 7,090 & 0,0279 \\
weibull & 2 & $-484,772$ & 973,656 & 13,300 & 0,0012 \\
exponencial & 1 & $-527,635$ & 1057,30 & 97,000 & $8,57 \mathrm{e}-22$ \\
normal & 2 & $-556,002$ & 1116,11 & 156,000 & $1,45 \mathrm{e}-34$ \\
\hline
\end{tabular}

Oligoryzomys nigripes

\begin{tabular}{lccccc}
\hline distribuição teórica & $\mathbf{k}$ & $\mathbf{l o g} . \mathbf{l i k}$ & AICc & $\Delta . A I C c$ & wi.AICc \\
\hline normal & 2 & $-89,9578$ & 184,582 & 0 & 0,2771 \\
weibull & 2 & $-90,218$ & 185,102 & 0,520 & 0,2136 \\
gamma & 2 & $-93,4105$ & 191,487 & 6,905 & 0,0087 \\
lognormal & 2 & $-96,2842$ & 197,235 & 12,652 & 0,0004 \\
exponencial & 1 & $-105,226$ & 212,663 & 28,081 & $2,21 \mathrm{e}-07$ \\
\hline
\end{tabular}

Brucepattersonius soricinus

\begin{tabular}{lccccc}
\hline distribuição teórica & $\mathbf{k}$ & $\mathbf{l o g . l i k}$ & AICc & $\Delta . A I C c$ & wi.AICc \\
\hline gamma & 2 & $-68,5912$ & 142,182 & 0 & 0,1844 \\
lognormal & 2 & $-68,779$ & 142,557 & 0,075 & 0,1528 \\
weibull & 2 & $-68,9549$ & 142,909 & 0,727 & 0,1282 \\
normal & 2 & $-70,6083$ & 146,216 & 4,034 & 0,0245 \\
exponencial & 1 & $-72,5845$ & 147,476 & 5,294 & 0,0130 \\
\hline
\end{tabular}

Delomys sublineatus

\begin{tabular}{lccccc}
\hline distribuição teórica & $\mathbf{k}$ & $\mathbf{l o g . l i k}$ & $\mathbf{A I C c}$ & $\Delta . \mathbf{A I C c}$ & wi.AICc \\
\hline gamma & 2 & $-272,518$ & 549,239 & 0 & 0,8843 \\
lognormal & 2 & $-275,236$ & 554,676 & 5,437 & 0,0583 \\
weibull & 2 & $-277,667$ & 559,537 & 10,298 & 0,0051 \\
exponencial & 1 & $-295,924$ & 593,915 & 44,676 & $1,76 \mathrm{e}-10$ \\
normal & 2 & $-299,757$ & 603,716 & 54,477 & $1,31 \mathrm{e}-12$ \\
\hline
\end{tabular}


Euryoryzomys russatus

\begin{tabular}{lccccc}
\hline distribuição teórica & $\mathbf{k}$ & $\mathbf{l o g . l i k}$ & $\mathbf{A I C c}$ & $\Delta . A I C c$ & wi.AICc \\
\hline gamma & 2 & $-262,093$ & 528,425 & 0 & 0,5003 \\
normal & 2 & $-263,368$ & 530,975 & 2,550 & 0,1398 \\
exponencial & 1 & $-265,01$ & 532,097 & 3,672 & 0,0797 \\
weibull & 2 & $-264,369$ & 532,977 & 4,552 & 0,0513 \\
lognormal & 2 & $-266,227$ & 536,693 & 8,268 & 0,0080 \\
\hline
\end{tabular}

Thaptomys nigrita

\begin{tabular}{lccccc}
\hline distribuição teórica & $\mathbf{k}$ & $\mathbf{l o g . l i k}$ & AICc & $\Delta . A I C c$ & wi.AICc \\
\hline gamma & 2 & $-120,609$ & 245,697 & 0 & 0,5841 \\
lognormal & 2 & $-123,61$ & 251,700 & 6,002 & 0,0290 \\
weibull & 2 & $-123,667$ & 251,814 & 6,117 & 0,0274 \\
exponencial & 1 & $-128,168$ & 258,489 & 12,792 & 0,0009 \\
normal & 2 & $-128,344$ & 261,167 & 15,469 & 0,0002 \\
\hline
\end{tabular}

M. incanus

\begin{tabular}{lccccc}
\hline distribuição teórica & $\mathbf{k}$ & log.lik & AICc & $\Delta . A I C c$ & wi.AICc \\
\hline lognormal & 2 & $-116,799$ & 238,142 & 0 & 0,1893 \\
gamma & 2 & $-116,831$ & 238,207 & 0,064 & 0,1833 \\
weibull & 2 & $-117,276$ & 239,097 & 0,955 & 0,1174 \\
normal & 2 & $-119,297$ & 243,139 & 4,996 & 0,0155 \\
exponencial & 1 & $-124,399$ & 250,971 & 12,828 & 0,0003 \\
\hline
\end{tabular}


ANEXO 7: Distribuições de densidade probabilística dos valores de distância máxima percorrida pelos indivíduos de sete espécies de pequenos mamíferos capturadas na Reserva Florestal do Morro Grande. Em azul, a distribuição teórica truncada em 223,6 metros melhor ajustada, em preto, a curva empírica dos dados. A linha contínua indica o quantil 0,9 e as linhas tracejadas os quantis de 0,60 a 0,85 e de 0,95 a 1 .

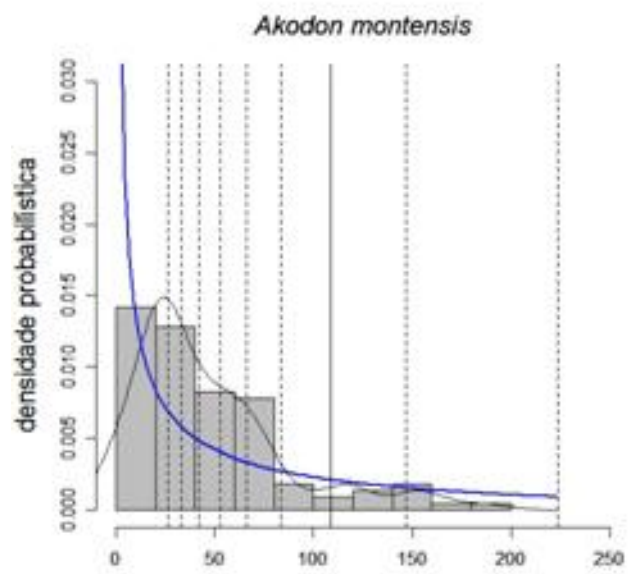

Euryoryzomys nussatus

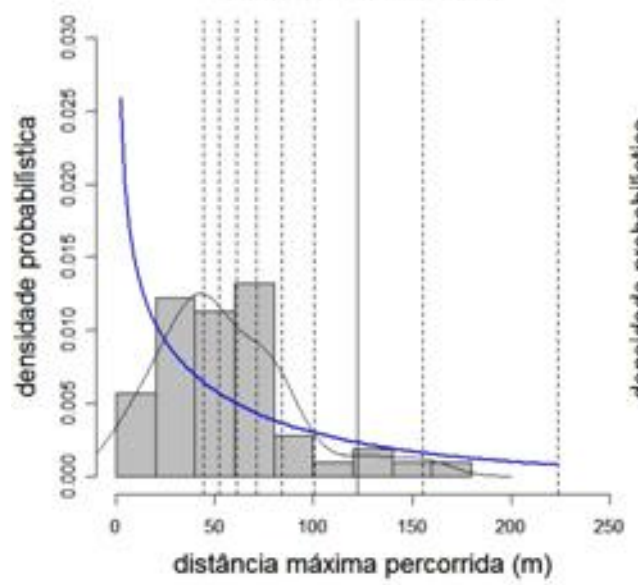

Oligoryzomys nigripes

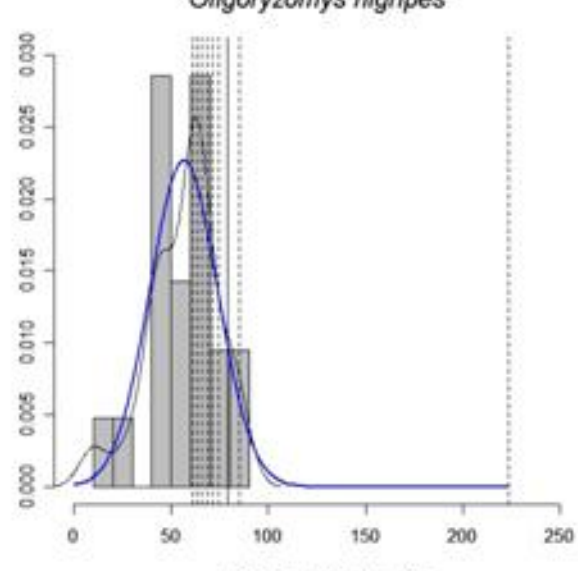

Thaptomys nigrita

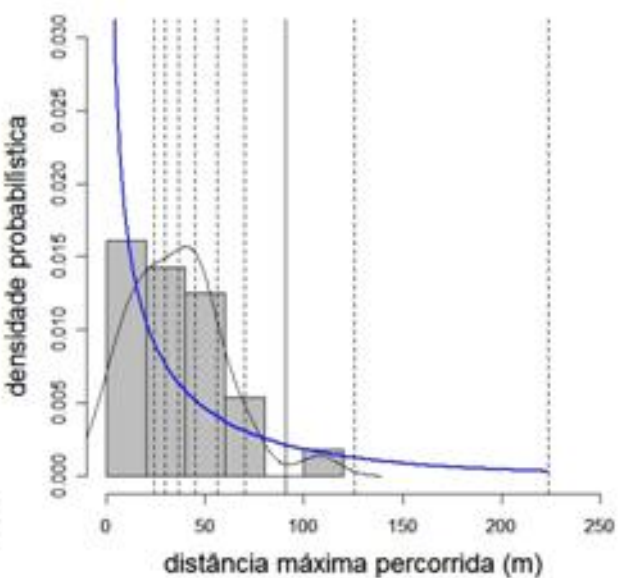

Brucepattersonius soricinus
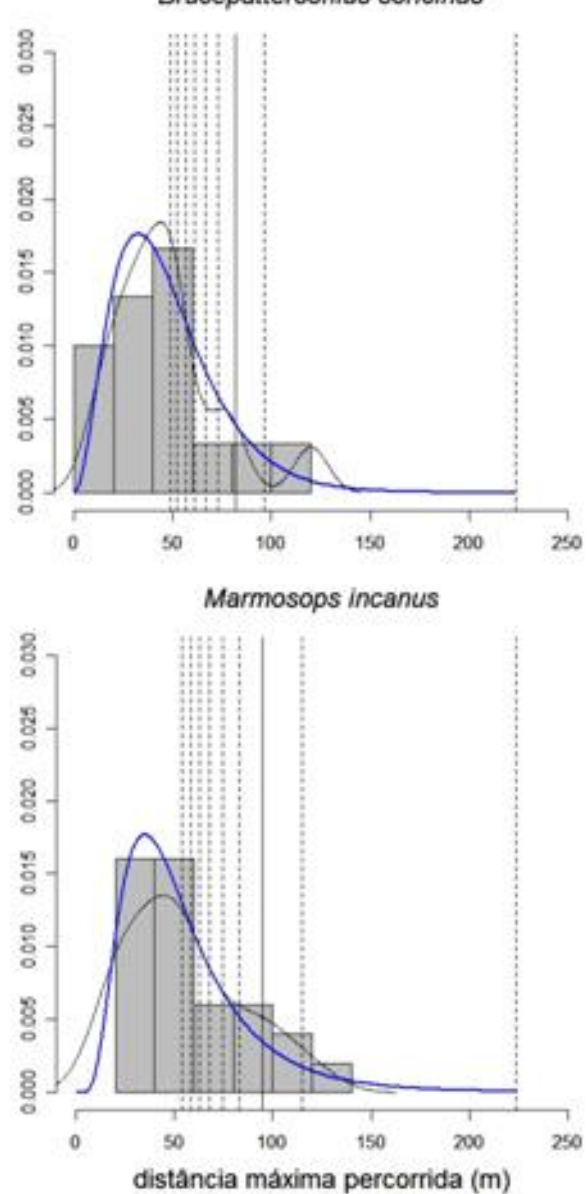

Delomys sublineatus

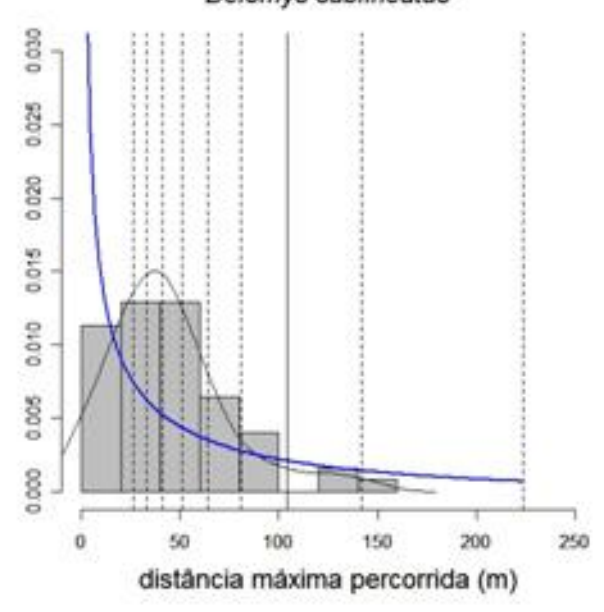


ANEXO 8: Resultado da seleção de modelos do risco de extinção em função da capacidade de dispersão, abundância local e amplitude de nicho para sete espécies de pequenos mamíferos capturadas na Reserva Florestal do Morro Grande. $\mathrm{k}=$ número de parâmetros; log.lik = máxima verossimilhança; $\triangle$.AICc = diferença entre o AICc do modelo considerado e do melhor modelo; wi.AICc= peso de evidência. Modelos selecionados estão sombreados.

\begin{tabular}{|c|c|c|c|c|c|c|c|}
\hline Modelo & Variáveis & Coeficiente & $\mathbf{k}$ & log.lik & AICc & $\Delta . \mathrm{AICc}$ & wi.AICc \\
\hline $\mathbf{A}$ & nulo & - & 2 & $-2,024$ & 11,048 & 0 & 0,6136 \\
\hline $\mathbf{E}$ & amplitude de nicho & $-0,525$ & 3 & 0,679 & 12,641 & 1,593 & 0,2767 \\
\hline D & abundância local & $-0,021$ & 3 & $-1,304$ & 16,608 & 5,560 & 0,0381 \\
\hline B & capacidade de dispersão (quantil 0.85) & 0,013 & 3 & $-1,480$ & 16,961 & 5,913 & 0,0319 \\
\hline B & capacidade de dispersão (quantil 0.90) & 0,004 & 3 & $-1,919$ & 17,838 & 6,789 & 0,0206 \\
\hline B & capacidade de dispersão (quantil 0.95) & 0,0001 & 3 & $-2,024$ & 18,047 & 6,999 & 0,0185 \\
\hline $\mathbf{C}$ & capacidade de dispersão (quantil 0.90) & 0,001 & 3 & $-6,584$ & 27,169 & 16,120 & 0,0002 \\
\hline $\mathbf{C}$ & capacidade de dispersão (quantil 0.85) & 0,002 & 3 & $-6,602$ & 27,204 & 16,156 & 0,0002 \\
\hline $\mathbf{C}$ & capacidade de dispersão (quantil 0.95) & 0,0004 & 3 & $-6,659$ & 27,318 & 16,270 & 0,0002 \\
\hline
\end{tabular}

